\title{
Causes and Consequences of Local Government Efforts to Reduce Risk and Adapt to Extreme Weather Events: Municipal Organizational Robustness
}

\author{
Patricio Valdivieso ${ }^{1, *(\mathbb{D})}$, Pablo Neudorfer ${ }^{1}$ and Krister P. Andersson ${ }^{2}$ (D) \\ 1 Faculty of Economic and Administrative Sciences, Universidad Austral de Chile (UACh), \\ Valdivia 5090000, Chile; pablo.neudorfer@uach.cl \\ 2 Institute of Behavioral Science, University of Colorado, Boulder, CO 80303, USA; krister@colorado.edu \\ * Correspondence: pvaldivf@gmail.com or patricio.valdivieso@uach.cl
}

Citation: Valdivieso, P.; Neudorfer, P.; Andersson, K.P. Causes and Consequences of Local Government Efforts to Reduce Risk and Adapt to Extreme Weather Events: Municipal Organizational Robustness. Sustainability 2021, 13, 7980. https:// doi.org/10.3390/su13147980

Academic Editors: David Tyfield, Rebecca Willis and Andy Yuille

Received: 5 May 2021

Accepted: 7 July 2021

Published: 16 July 2021

Publisher's Note: MDPI stays neutral with regard to jurisdictional claims in published maps and institutional affiliations.

Copyright: (c) 2021 by the authors. Licensee MDPI, Basel, Switzerland. This article is an open access article distributed under the terms and conditions of the Creative Commons Attribution (CC BY) license (https:/ / creativecommons.org/licenses/by/ $4.0 /)$.

\begin{abstract}
This research article investigates the causes and consequences of municipal institutional arrangements for the provision of resilient critical infrastructure in municipalities. The study explains how the municipal organizational robustness and external institutional dynamics moderate the relation between capacities, leadership, and local government investment decisions. We examine hypotheses on moderating effects with regression methods, using data from 345 Chilean municipalities over a nine-year period, and analyzing the evidence with support of qualitative data. Our results reveal that municipal organizational robustness-operational rules, planning, managerial flexibility and integration, and accountability-is the most quantitatively outstanding moderating factor. The evidence leads us to deduce that efforts to support local governments in the emerging policy domain of resilient critical infrastructure require special attention to the robustness of municipal institutional arrangements. The results are valid for countries where the local governments have responsibilities to fulfill and their decisions have consequences for the adaptation. Since one of the objectives of the Special Issue “Bringing Governance Back Home-Lessons for Local Government Regarding Rapid Climate Action" is to explore how action is enabled or constrained by institutional relations in which the actors are embedded, this study contributes to achieving the goal.
\end{abstract}

Keywords: local governments; critical infrastructure investment; capacities; political leadership attributes; municipal organizational robustness; governance; Chile

\section{Introduction \\ 1.1. Research Question}

Capacities and leadership are important ingredients of effective local government responses to frequent disasters and climate change [1-3], but how are the capacities and leadership translated into decisions and adaptation outcomes? To address this research question, this study investigated the causes and consequences of municipal institutional arrangements and governance relationships in shaping local government decisions to reduce risk and adapt to extreme weather events through investment in resilient critical infrastructure. The study contributes to new knowledge related to the organizational dynamics of disaster risk reduction (hereafter DRR) and adaptation in two ways. First, we draw on a broad literature to articulate a theoretically plausible set of hypothetical relationships between municipal institutional arrangements, governance relationships, and local governments investment decisions for critical infrastructure. While numerous previous studies have pointed out that local institutional arrangements are often important determinants of adaptation performance, and our previous work has helped identify several relevant factors [4], this research contributes more specific knowledge about how municipal organizational dynamics matter. Second, we used mixed research methods to assess these relationships empirically for a large number of local governments in Chile. 
Critical infrastructure provides services that are essential to the normal functioning of a society [5,6], minimize the risks of multiple hazards, and reduce the impacts of climate change [7-11]. In high-income countries, the main emphasis for infrastructure is maintenance (hereafter Maintenance), whereas in low- and middle-income countries, the challenge is investment in building infrastructure (hereafter Investment) to cover basic needs [12-15].

Through decisions, local governments play an important role in DRR, mitigation, adaptation, and sustainable development in terms of Investment and Maintenance $[3,13,16]$. The local government decisions and outcomes are shaped by complex situations-biophysical, social, and institutional dynamics - that give rise to uncertainties, incentives, and opportunity costs $[3,17,18]$.

\subsection{Scope and Contributions}

It is relevant to know more about the institutional causes and consequences of multiple efforts to reduce risk and adapt to extreme weather events. International frameworks, academic studies, and empirical evidence converge around the urgent need to increase efforts to improve critical infrastructure as a way to reduce vulnerability and improve coping capacities and resilience [3-9,12,13]. Local governments share the responsibility to provide resilient infrastructure [3,13]. However, improvement has been unhurried, especially in municipalities of low- and middle-income countries, where an important part of the population live at risk due to deficits on critical infrastructure [13]. Therefore, we are in need of knowledge to understand the breach between infrastructure needs and local government decisions.

Conceptual reasons suggest that the gap between demand and supply will persist where institutional conditions and constraints negatively affect local government performance [17-28]. Hence, further research and evidence-based knowledge are required to understand how municipal institutional arrangements shape public infrastructure outcomes, and how improvements may trigger local government performance. Despite growing interest in critical infrastructure [6,9-12,14,15], there is still insufficient empirical evidence about how municipal institutional arrangements and governance processes shape local governments' outcomes $[3,13]$. The conventional literature on infrastructure approaches the subject mainly from a technical-economic perspective [9-11,14,29-33]. The literature on sustainable development, DRR, climate change mitigation, and adaptation in cities and municipalities (hereafter sustainable cities literature) has integrated research frameworks and theories on organizational behaviors and governance relationships [1-4,13,34,35]. Some studies analyze experiences or compare cases of local governments that often are already committed to a transition [1-3,34-36]. However, more attention should be given to institutional dynamics (e.g., municipal institutional arrangements and governance processes) shaping decisions and outcomes in typical local governments (committed or not to address climate change or natural DRR), particularly in low- and middle-income countries.

One of the clear conclusions of the previous literature is the role of leadership. However, the issue of leadership is not really addressed sufficiently. Acknowledging this weakness in the literature, the exhaustive review by the Working Group II to the Fifth Assessment Report of the Intergovernmental Panel on Climate Change states that there is less research on local government decisions to include adaptation in plans and investment programs [13]. Our study with Chilean municipalities contributes to fill this gap enhancing the understanding of how municipal capacities and some political qualities that increase the effectiveness of the mayoral leadership are translated into institutional decisions. The analysis produces evidence in relation to how variables that represent municipal institutional arrangements and governance processes moderate the effects of variables that represent capacities and political leadership attributes in local government decisions regarding Investment. Through this result, we know that the municipal organization robustness is what explains how the capacities and motivation of leaders lead to concrete local government decisions in terms of adaptation. A robust municipal organization involves a consistent 
set of norms, operational rules, units, positions, and programs, guided by the explicitly stated organizational goals related to critical infrastructure. The coordination mechanism between departments, planning, integration, accountability, and transparency (e.g., responsibility, liability, access to accurate information) ensure local government decisions based on effective communication and congruent behavior by all its members.

Since no full-blown theory of local government decisions existed until now, the literature on the subject proposes a varied set of possible institutional drivers affecting local government decisions [3]. We focused our research on understanding how municipal institutional arrangements and governance processes interact with both capacities of local governments and political qualities of the mayoral leadership (hereafter political leadership attributes). Capacities and political leadership attributes that support motivation have been identified by one part of the sustainable cities literature as key factors in shaping outcomes [1-4,13,35-38]. Hence, we start from the assumption that in order for municipalities to be effective adaptors in terms of critical infrastructure Investment, they need to be organizations with resources (capacities) and have highly motivated agents with political leadership attributes (e.g., networks, support, continuity). If they do not have these qualities, the likelihood that they will be effective decreases $[1,2,13]$.

Theories on institutions, organizational behaviors, and governance relationships appeared to be a suitable way to explore the Chilean experience with regard to how capacities and leadership are translated into institutional decisions and outcomes. The institutional dimension can be broadly divided into internal processes related to issues of municipal organization, on one hand, and interactive external dynamics of governance on the other [3].

Therefore, we sought to understand if and how municipal organizational arrangements and governance relationships moderate the connection between capacities, political leadership attributes, and local government Investment in almost all typical Chilean municipalities (345 out of 346). We examined the validity of the conjecture on moderation effects with regression methods and interactions, using longitudinal data for almost all Chilean municipalities over a nine-year period, analyzing the findings with the support of qualitative evidence. Despite our focus on moderation effects, we are aware of the challenge of measuring causality with the observed data and interactions between variables. We face the challenge with the control function, the treatment of variables, and describing relationships in conditional rather than general terms $[39,40]$. To give order and direction to our exploration, we proposed the following ex ante hypotheses:

Null Hypothesis 1: The effects of capacities on Investment (Maintenance) are direct and independent. Capacities consist of resources available within the municipality and include financial, human, and professional expertise $[1-3,13,35,38]$. Hence, regardless of institutional moderators, capacities are always the key factor for Investment. Alternative 1: The relationship between capacities and Investment (Maintenance) depends on the interactions with municipal organizational arrangements or governance relationships.

Null Hypothesis 2: The effect of political leadership attributes on Investment is not affected by municipal or external institutional dynamics. The effect of political leadership attributes of the mayors and/or senior staff in their own right are documented by a large number of sustainable cities studies [1-3,37]. Some attributes that enable actions of leaders are agency and power in terms of electoral, political, and institutional support, and continuity $[3,4,36,37]$. Alternative 2: Municipal organizational arrangements or governance relationships affect the direction and strength of the relation between leadership and outcomes.

We tested Alternative Hypotheses 1 and 2 guided by a growing case-based literature on organizational behaviors suggesting that capacities and leadership have conditional effects [3,4,34-36,41-44].

Our results reveal, on one hand, that the observed heterogeneity in Investment and Maintenance decisions at the local government level in Chile is associated with both capacities and political leadership attributes, leadership being the most quantitatively 
outstanding ingredient. On the other hand, the evidence also shows that municipal organizational arrangements such as operational rules, accountability, planning, interdepartmental coordination, and municipal integration moderate the effects of both capacities and political leadership attributes in Investment. Even though governance relationships have moderation effects, the results reveal that internal organizational arrangements are more quantitatively relevant. The evidence leads us to deduce that efforts to support local governments in the emerging policy domain of resilient critical infrastructure require special attention to the robustness of the municipal organization.

The study is structured as follows. First, Background (Section 2) explains why Chile is a suitable case to explore relationships between municipal organizational arrangements and governance dynamics driving local government to advance in Investment. Literature Review (Section 3) summarizes and analyzes theories and evidence from studies. Modeling Moderating Effects (Section 4) presents the approach we implemented to analyze moderation effects. Methodological Design (Section 5) explains the steps of research. Results (Section 6) contains the evidence and our analysis with the support of qualitative evidence. The conclusions summarize the implications that emerge from the analysis.

\section{Background: Chilean Case}

Chile is a suitable case to analyze the institutional causes and consequences of local efforts to adapt (Figure 1). The country is a unitary republic with national ministries, 16 regions, and 346 municipalities [3,45-49] (Figures A1-A3 in Appendix D). The municipalities have mandates, budgetary autonomy, and staff to design and execute local development plans, under the leadership of elected mayors and municipal councils [50]. Most of the municipal territories require Investment [4,51-54]. The period 2009-2016 is particularly interesting to explore, because it was a time of transition from an extremely centralized state toward greater autonomy at the subnational level [51,55].

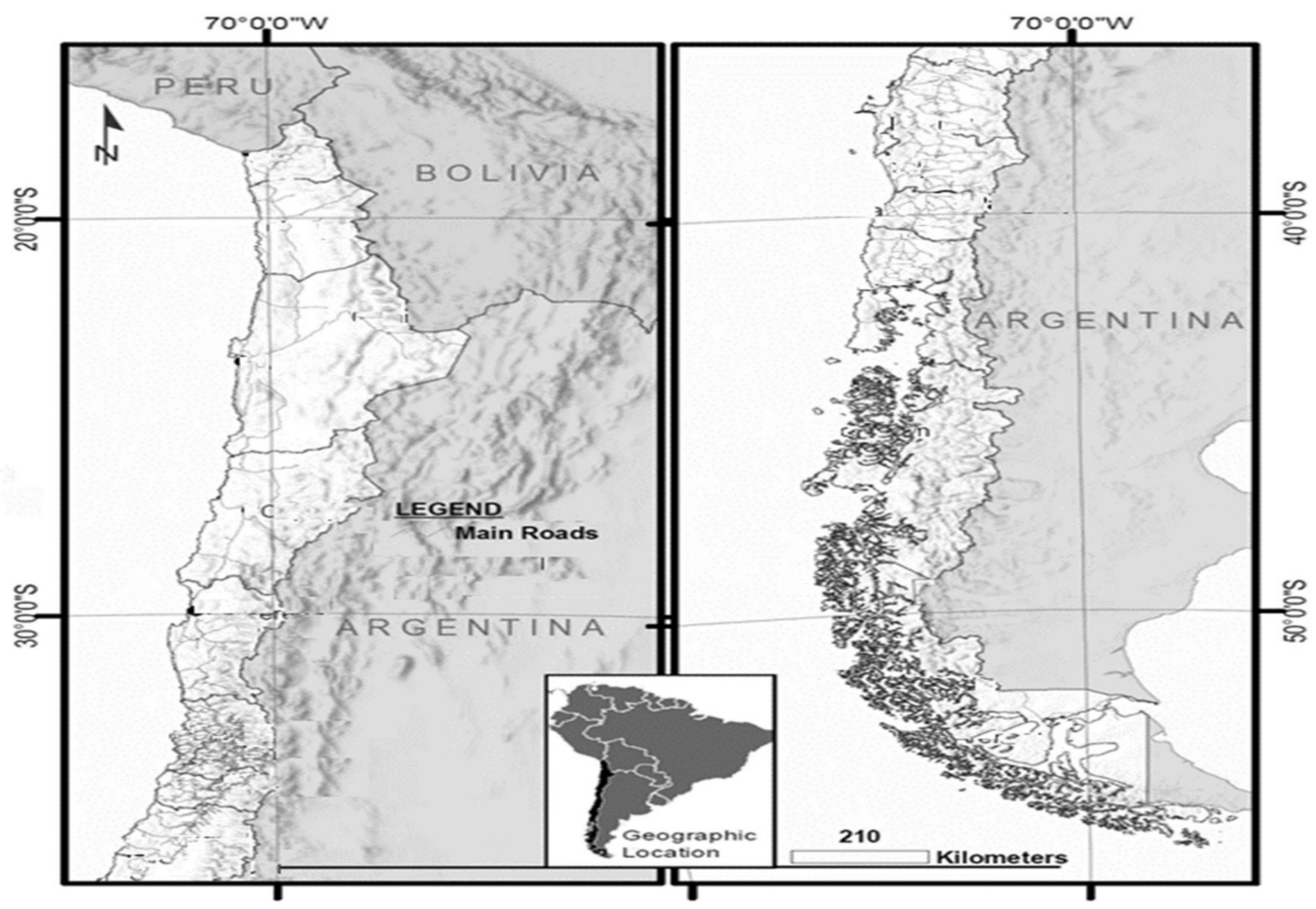

Figure 1. Chile in South America, northern part on left and southern part on right $[45,46,56,57]$. 
Traditionally, Chilean municipalities fulfilled functions of providing very basic services, such as cleaning, garbage collection, and maintaining public goods [51]. Since the mid-2000s, a set of national policies prescribed more functions and powers for local governments with the expectation of proactive provision of public goods and Investment $[3,49-51,55,58]$. At the same time, increasing awareness regarding the environmental conditions motivated transitional national policies on adaptation [54,55,59-83].

Almost all Chilean local governments had the same possibilities to advance proactively in the emerging policy sphere of DRR, climate change adaptation, and Investment, but there were striking contrasts in how local governments progressed [47,51-55,60-62,82,83].

The only existing survey of 98 representative municipalities in nine regions, where $90 \%$ of the country's population lives, directed at municipal senior officials, reveals a high degree of variability in the goals of climate change adaptation and planning, DRR, and engagement with Investment, which motivates questions regarding evident inconsistencies [56]. On one hand, manifesting a high degree of recognition of climate change, $95 \%$ of the interviewed officials reported they really believe climate is changing and more negative events will be produced by the change; $84 \%$ said that the mayors champion policies, planning, and actions to move forward into climate change adaptation. On the other hand, $42 \%$ reported the issue was a priority for the local government, and only $37 \%$ said that municipal staff officials agreed with those goals. Asked if the local government engages with Investment for DRR and climate change adaptation, $78 \%$ provided information about prevention routines to reduce damages caused by emergency situations, and only $38 \%$ said actions are taken toward Investment in terms of DRR, mitigation, or climate change adaptation $[5-8,12,13,84,85]$. Only $37 \%$ agreed that their municipalities are prepared to face climate change.

\section{Literature Review}

Much of the current literature on public infrastructure discusses needs and options for resilience of critical infrastructure [6-9,12,14,15,29-33,85], but overlooks the institutional reasons for variability in local government performance [1-3,16,86-88]. One part of the available literature on sustainable cities addresses institutional contexts that shape local government decisions $[1-3,5,13,18,23,34-37,41-44,88-90]$. However, until now, we have known far too little about how those dynamics explain critical infrastructure investments in typical municipalities, like in Chile.

Because there is not a full-blown theory connecting explanatory components with local government outcomes $[3,17]$, we assume that several institutional factors may influence local government decisions, for example capacities, governance, leadership, and political factors, among others [3-5,91]. To focus on hypotheses about institutional moderators, we selected capacities and political leadership attributes as factors that may have direct and independent effects on local government investment decisions, on one hand, and municipal organization arrangements and governance relationships as potential moderators on the other. The review of literature seeks to understand how the selected institutional factors and processes may affect local government decisions and outcomes.

\subsection{Capacities}

In the sustainable cities literature, budgetary resources, workers, and skills are essential for effective DRR and adaptation [1-3,13,38,89-95]. One assessment in the review by the Working Group II to the Fifth Assessment Report of the Intergovernmental Panel on Climate Change states that financial capacities provide a foundation for city resilience on which adaptation can be built [13]. Still, local government performance also depends on participation, commitments, will, and institutional plans toward goals $[3,35,41,55,96,97]$.

Human resources with regard to staff, work time, managerial, and staff competences seem to be another relevant dimension of capacity [1-3,13,34,90-98]. The emerging policy spheres of adaptation planning, investment, and implementation of new resilient infrastructure, for example, require permanent staff with technical understanding $[29,92,94,98]$. 
Staff, however, may have commitments to managerial routines, rejecting adaptation if perceived to have no valued benefits $[1,2,18,36,44,89-100]$.

In terms of cognitive capacity, procedural and enabling skills facilitate the mobilization of resources to reach specific goals [101]; for example, trained professionals can frame issues and use skills to apply methods. The literature on sustainable cities exhibits evidence of the relevance of knowledge and skills for planning [1-3,23,29,93].

\subsection{Leadership}

An increasing number of studies address the role of agents, ideas, and agendas in organizations and political processes [1-3,36,37]. In contexts where new policy spheres for action are emerging, leadership has become conceptualized as the driver of organizational behavior [2,102-104]. Nevertheless, leaders need opportunities, supportive networks, and conducive political contexts to advance in their agendas [3-13,34-36,42,105-112].

In municipal organizations, leaders are frequently elected officials or senior managers. For example, historically, city mayors have played an important role in the USA [103]. The literature of sustainable cities has highlighted the importance of leadership for DRR and adaptation, reporting actions of individuals $[2,3,113,114]$. Nevertheless, in typical local governments, mayors and senior officials also may obstruct initiatives, depending on how they and/or their supportive networks understand the issues and incentives [36,55].

Leaders may be motivated by several processes and mechanisms such as organizational incentives, changes in the intellectual climate of ideas, and systemic interactions $[35,44,115,116]$. In democratic systems, the behaviors of leaders are linked to sources of support $[41,103,117]$. Factors such as electoral motivation and continuity influence decisions and outcomes $[109,118]$.

In the municipalities, mayors or senior officials may use strategies rationally to advance goals $[2,89,103]$. However, municipal leaders need the support of municipal councils, staff, constituents, stakeholders in society, and regional and national governments [2-4,18,25,34-36,42,54,90-92,94,98-101,103,108,110,119].

\subsection{Municipal Organization}

Sociopolitical outcomes are driven in part by political institutions, for example, electoral systems and encoded prescription [41,44,86,109,120-122].

One part of the institutionalist literature conceptualizes organizations as institutionalized social norms that are sources of stability and order [41,120-124], i.e., resilient encoded prescriptions, operational rules, and restrictive organizational templates [87,124]. As structure, organizations consist of units, positions, and programs linked by explicit goals. These components explain shared institutional logics and patterns of relationships.

Another part of the literature highlights that individual behavior of utility-maximizers drive decisions in organizations [99,120,125-127]. Organizational behavior is the consequence of the interlocking choices by maximizer individuals and subunits, each acting in terms of expectations, preferences, and rational choices. However, since individual behavior in organizations is embedded within prevailing organizational logics, the free play of individual will and calculation have restrictions.

Public organizations and staff tend to reproduce routines, with little room for innovations [128]. According to Tullock [99], staff professionals are inclined to be reluctant to change because they want to minimize risks. Since security is defined as maintenance of routines, achieving many objectives simultaneously (e.g., income, position), according to Downs [22], staff professionals prefer the status quo and fear change.

Organizational hierarchy and compartmentalized functions hinder functional efficiency. To overcome the challenge and increase robustness (the property of being strong to achieve organizational goals), Downs [22] proposes that all organizations should institutionalize some kind of coordination mechanism and procedures. These ideas are close to what is understood in sustainable cities literature as robust institutional arrangements, 
accountability, and transparency [3,13,129-131]. Robust organizational arrangements may enrich governance outcomes [13].

The theories of organizational dynamics shed light to understand trajectories and compare local government experiences regarding DRR, climate politics, and adaptation planning. Sustainable cities scholars have made great strides in showing how internal organizational contexts affect adaptation planning $[2,3,5,18,23,35,36,55,89,90,101,114,132,133]$. For example, operational rules combined with competing development considerations may limit municipal agendas [1,2]. Municipal organization in terms of council-manager and mayor-council may have effects on municipal outcomes [133]; councilors prioritize issues depending on their agendas [55].

The literature of sustainable cities shares a consensus around the benefits of planning to advance in adaptation [1-3,13,34-36,90,96,97,100,133,134]. In some cases, DRR or adaptation planning in specialized units increases coordination, integration, and consistency in organizational structure $[96,133]$.

\subsection{External Institutional Dynamics and Governance Relationships}

Positivist legal theories identify the state as a legal order with binding authority over all actions taking place within its area of jurisdiction [135] but norms are interpretable and applied by agents [17,123,124,136].

Structural functionalist approaches shed light on systemic dynamics shaping outcomes such as interactions between the institutional environments and organizations [119,121,122,124,137]. Organizations are conceptualized as parts of a larger system, subsystems with multiple overlapping connections $[17,87,121,137]$. Stimuli, reactions, and feedback processes induce resilient maintenance, adaptation, or change [119,122,124,137-141].

In game theory frameworks, a variety of interactive dynamics between goals, strategies, structures, roles, and rational choices make players in each game use other players for their purposes $[17,87,142]$. Through these processes, diffusion and cooperation may occur, producing functional results $[143,144]$. Therefore, macro- and middle-level action arenas, such as national and regional, and decisions on policies and plans may affect contexts and behaviors of local governments.

Recognizing this type of dynamic, scholars from several disciplines converge around the concepts of multilevel governance as explanans of outcomes [3,17,43,145,146]. The literature on sustainable cities reports on external dynamics, incentives, and interactions influencing local governments' decisions [1,3,13,42,43,147-152]. For example, national and subnational policies of climate change adaptation [1-3,13,100,115,117,132], international regimes $[3,4]$, agencies, and several networks championing mitigation and adaptation $[1-3,42]$.

Until now, theories and scholarly contributions linking integration, network, and governance relationships have exercised a strong influence on the research agenda and public policies for sustainable cities [3,5,12-14,42,43,85]. Hence, the external institutional dynamics and governance relationships may have moderating effects on the relationships between capacities, leadership, and local government decisions.

\section{Modeling Moderating Effects}

Situating the analysis in the Chilean context, where there is an urgent need for more resilient infrastructure [51-53,60], we assume that Investment is desirable. Hence, the analysis seeks to understand how the capacities and political leadership attributes in the Chilean municipalities translated into local government decisions in Investment. In this section, we display the model specification for the analysis.

\subsection{Considering That Several Local Governments Do Not Invest in New Projects}

The dependent variables under analysis are Investment (in new infrastructure) and Maintenance (of current infrastructure). The data of our sample of 345 municipalities show that all local governments in Chile invest in Maintenance [82] (Table A2 in Appendix B), 
which is easier and cheaper than investing in new infrastructure (i.e., Investment). Several local governments do not invest in new projects at all. As discussed (e.g., Null hipotheses, Literature Review), the drivers of the low or null investment are arguably driven by low municipal capacities (financial, human) and/or weak political leadership attributes.

Since several local governments do not invest, the variable Investment is nonlinear (e.g., local governments with zero Investment). This situation is referred to as a corner solution and the standard linear model is not the best methodological approach in this setting [153]. Hence, we implemented a Tobit regression model specifying that the investment variable is limited from the left at zero. Formally, the expected value of the annual investment per inhabitant at $t$ in municipality $i$ is defined as

$$
E\left(y_{i t} \mid X \beta\right)=\operatorname{Pr}\left(y_{i t}>0 \mid X \beta\right) * E\left(y_{i t} \mid X \beta, y_{i t}>0\right)
$$

Equation (1) assumes that the expected investment among municipalities and across time, $y_{i t}$, depends nonlinearly on a vector of variables $X$ and a vector of parameters $\beta$. The nonlinearity arises when we observe that for some municipalities and some time periods, $\operatorname{Pr}\left(y_{i t}>0 \mid X \beta\right)=0$, which is the source of the observed null investment for some local governments.

\subsection{The Moderating Effect of Municipal Organization Arrangements and Governance Relationships}

According to the Alternative Hypotheses and literature review, effects of capacities and political leadership attributes may be part of a configuration of factors moderated by municipal organization arrangements and governance relationships (hereafter institutional dynamics). Assuming that moderation arises where the association linking the independent and dependent variables is conditional on other variables, moderating effects are specified as multiplicative terms (e.g., interaction) $[39,40,154]$. To gain insight into how the conditioning effect works, we present the following illustrative standard linear model, Equation (2):

$$
y_{i t}=\alpha+\beta_{1} x_{i t 1}+\beta_{2} x_{i t 2}+\beta_{3} x_{i t 3}+\beta_{4} x_{i t 1} x_{i t 3}+\text { Controls }+\gamma_{t}+\gamma_{i}+\varepsilon_{i t}
$$

Equation (2) defines that the output variable is driven by $x_{i t 1}$ (e.g., capacity variables), $x_{i t 2}$ (e.g., political leadership attribute variables), and $x_{i t 3}$ (e.g., institutional dynamics). The last variable plays a double role: a direct effect, and a moderating effect between $x_{i t 1}$ and $x_{i t 2}$ and $y_{i t}$. In our setting, the direct effect is seen as a control to concentrate on the moderating effect. We assumed that the error term, $\varepsilon_{i t}$, is a zero mean independent and an identically distributed random component. Particularly, we assumed that, conditional on all included control variables, $\varepsilon_{i t}$ is independent of $x_{i t 1}, x_{i t 2}$, and $x_{i t 3}$.

\section{Methodological Design}

The main goal of this research study was to produce findings related to the expected moderation effects of institutional dynamics. We designed procedures to test hypotheses about how municipal organization arrangements and governance relationships may affect investment decisions in critical infrastructure and maintenance. Next, we summarize the methods used with their respective advantages and limitations.

\subsection{Quantitative Analysis: Case Selection Variable, and Data Analysis \\ 5.1.1. Case Selection}

To explore evidence around the Alternative Hypotheses on moderating effects of institutional dynamics (i.e., municipal organization arrangements and governance relationships), we included in the analysis almost all Chilean municipalities (345 out of 346). All of the subnational territories and communities are affected by deterioration of environmental conditions, frequent disasters, and climate change and require more investments in resilient critical infrastructure $[45,47,51-55,57,59-83,155-176]$. 


\subsubsection{Variables}

We evaluated a wide set of potential dependent, independent, and moderation variables considering the availability of data and selected those that best fit the research question and hypotheses of our study (variables described and justified below). We carefully selected metrics that best fit the concepts of the hypotheses, collecting reliable data from several public sources with available information (e.g., national, regional, and municipal), and by request (Figures 2-5).

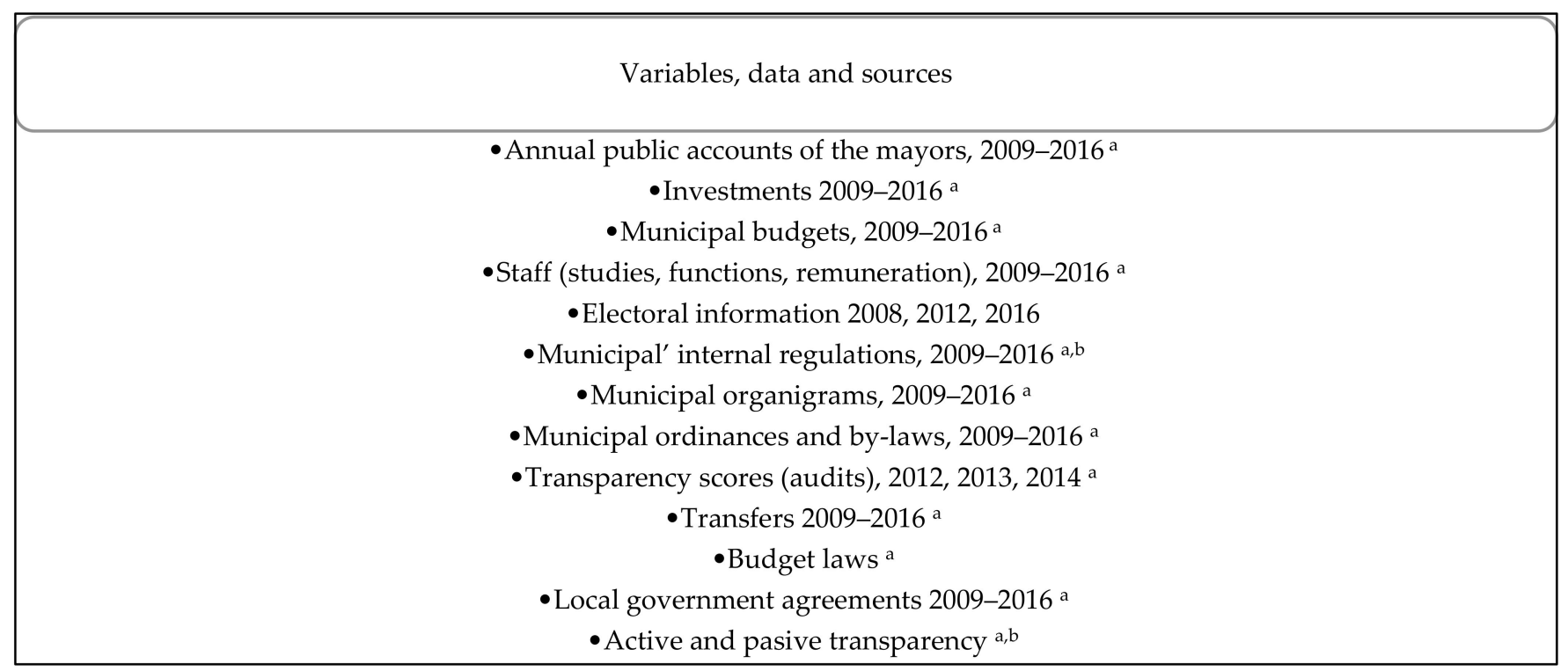

Figure 2. Explanans and explanandum variables, data and sources. ${ }^{a}$ Municipal secretaries, planning offices, websites, and by request (Figures 2-5, data source [82,177-180]). ${ }^{b}$ Requests for Transparency for the following pieces of information, from 345 municipalities: (1) questionnaire with 25 questions regarding consulting information on categories included in the Municipal Organization Index, with 260 written responses (via Municipal Secretary and Transparency Office) and a chronological record of submissions and responses, December 2015 to April 2016; (2) requests to complete information not available on municipal websites or other sources of information (e.g., years of annual accounts, minutes of municipal councils, budgets), with chronological record of submissions and responses April 2014 to December 2020.

We are aware of possible limitations of the availability of data and selected variables for the quantitative analysis. For instance, the fact that local governments with motivated mayors enjoying electoral support are more adaptive in terms of critical infrastructure investment is shown in the data, but this may be due to factors that we could not observe with our data. Due to data constraints, we could not consider in the analysis all possible factors that the previous literature of cases suggests are relevant for adaptation, for example, business needs, framing, or social trust [4]. We faced this issue using a rich set of controls at municipal level (data sources, Figure 3).

Investment and Maintenance. In Chile, local governments have some responsibilities that are shared with other organizations [51]. For example, investments in education, health, and security are determined by the ministries, and the municipalities collaborate in local planning and implementation. The same happens with housing subsidies, which are not in the domain of local government investment decisions. Therefore, the study focused only on investments that depend on local government decisions, which, according to the results of official surveys applied during the study period, were demanded by the citizens. We used Investment and Maintenance as dependent variables [82]. During 2009-2016, new critical infrastructure were designed to cover citizens' needs and development goals, complying with national standards (e.g., DRR, adaptation, and environmental protection) $[6,12,60-62,82]$. The projects were designed by the municipalities (study, preinvestment, project design, and execution), and the local governments financed the costs with their own resources and by applying for funds at national and regional levels [82]. 
The designs were very time-consuming and expensive and required specialized studies and evaluation stages. Maintenance projects cost less for preparation in terms of financial resources, personnel, and studies, and the approval was faster $[4,82]$.
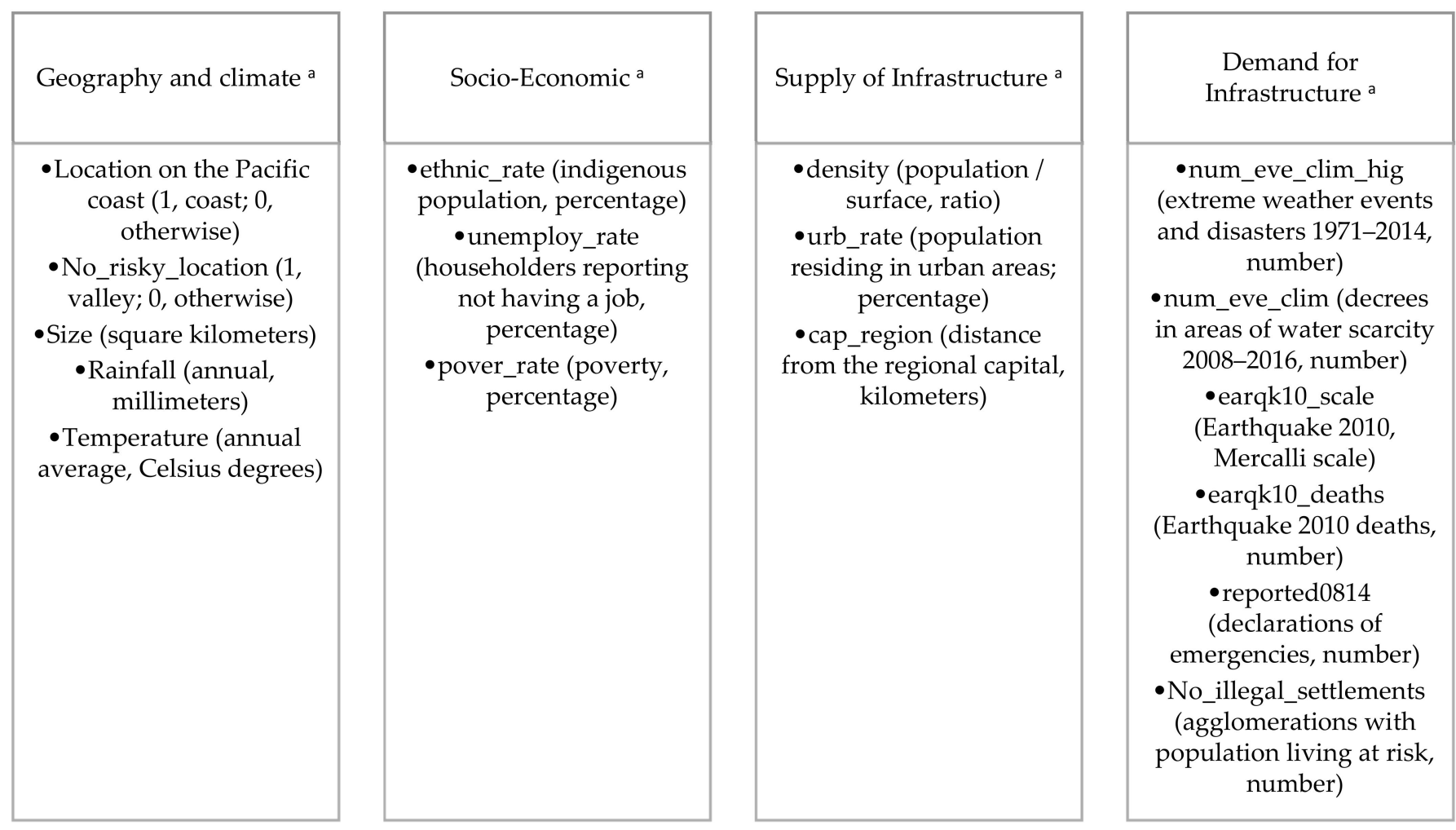

Figure 3. Control variables, data and sources. ${ }^{\text {a }}$ Reliable data from several public sources with available information $[47,48$, $53,57,63,68,73,76,79,85,167,168,170-172,175,181]$.

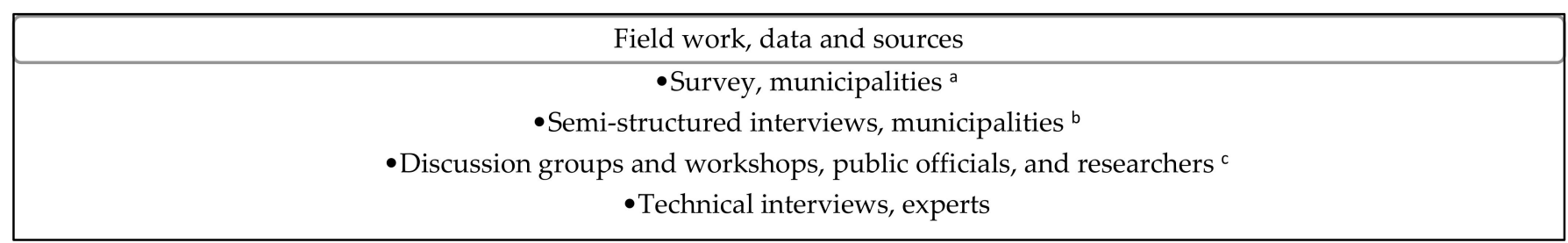

Figure 4. Interviews. ${ }^{\text {a }}$ Face-to-face survey with semi-structured questionnaire conducted by the contracted professional Group Demoscopica with 159 senior functionaries of 79 municipalities in nine regions (directors of environment, civil protection and emergencies, planning, public works, and social organizations), between April 2015 and March 2016, and conducted by research staff of the Project FONDECYT with 45 senior functionaries in 19 municipalities between April 2015 and December 2016 [56]. ${ }^{b}$ Senior officials, five in each municipality (average). Chronological record of interviews: March to June 2014, October 2014 to October 2018. ' Discussion groups organized with representatives of national, regional, and municipal offices, academic seminars, and workshops with a chronological record April 2014 to April 2021 [56].

For the selection of dependent variables-Investment (in new critical infrastructure) and Maintenance (on existing infrastructure)—we considered the information we had on the Chilean context (see Background: Chilean case; interviews, Figures 1 and 4, Figures A1-A4), particularly evaluations made by ministries and international organizations of the need for critical infrastructure investment in the municipal territories [51,59,60,62]. Regarding the quality of our data, we are convinced that the measures for the two dependent variables that we used in the analyses are both accurate and reliable. We made this assessment based on two factors: (1) These are official data that are used by the government to make public funding 
allocations, and as such the data and the process that generates them undergo repeated internal checks and controls (e.g., audit process associated with the production of these data) by the Budget Directorate of the Ministry of Finance and the Office of the General Comptroller of the Republic. (2) Our classification of the data in two separate categories for the creation of our two dependent variables was informed by personal interviews with representatives of national, regional, and municipal officials and experts (Figure 4). We consulted these authorities to be sure that our classification was accurate. For these reasons, we are confident that our dependent variables data reflect real local investments in these categories.

In relation to the independent and moderation variables, we considered a wide set of potential variables and availability of data. We carefully selected as variables those metrics that best manifest the concepts of the hypotheses, collecting reliable data from several public sources with available information (e.g., international, national, regional, and municipal), and by request (see data sources in Figures 2 and 5). For example, for national resource transfers, we considered transfers intended to improve resilient infrastructure, i.e., special funds for roads, sanitation infrastructure, development of local initiatives, and neighborhood improvement funds. While these funds aim to support municipalities' efforts toward new investments, local governments decide autonomously whether or not to invest in such areas. The procedure consisted of (1) a review of expenditure items in national budgets to identify such funds and (2) a review of annual budgets of ministries and regional governments in the national databases administered by the Ministry of Finance to identify all transfers made in the period 2009-2016. Next, we describe the variables (see descriptive statistics in Tables A1 and A2, Appendices A and B).

Municipal capacities. We included the variable "partFCM": proportion of the total municipal budget from the Municipal Common Fund (MCF, or FCM in Spanish) [32], which is a redistributive scheme in Chile [34] (see data source Figure 2). The variable reflects long-term relative budgetary deprivation, which in turn identifies municipalities historically less developed [48]. Since Chile had consistent growth during 2009-2016 [182], we expected municipalities with few infrastructure measures to have a high MCF and to invest relatively more in new projects compared to Maintenance because they do not have much infrastructure to maintain [51].

We included the following conditional exogenous variables as proxies of human capacities (e.g., the variables are independent on the error terms once controls are included in the regression): (1) proportion of employees working in the environmental field, (2) proportion of employees working on civil protection and emergencies, (3) proportion of employees holding a bachelor's degree (measures staff professionalization), and (4) mayor's education level (see data sources in Figure 2). More intense human capital may be associated with higher levels of Investment [1-3].

Leadership, political viability/support. Considering the Chilean context (e.g., lack of critical infrastructure, climatic change, frequent disasters, citizen needs, constitutional norms, national policies, centralized governance) and interviews in municipalities $[3,48,49]$ (Figures 2 and 4), we presumed the mayors should be motivated by Investment in resilient critical infrastructure. Hence, regarding viability, we selected the following variables as proxies of qualities that may enable actions of the mayors $[2,3,35,36,102,103,109,118,177]$ : (1) the proportion of the mayor's winning votes reveals electoral support and commitment to citizens' needs, (2) the proportion of members of the municipal council in the same political coalition as the mayor represents support, (3) the mayor's belonging to the ruling party indicates political support, and (4) the mayor being in a second term indicates continuity (e.g., experience), (see data sources in Figure 3). High levels of political leadership attributes may be associated with higher levels of Investment.

Municipal organization. We used three variables to measure municipal organizational robustness. First, autonomy of the municipal council is a rate index based on reading and coding available council regulations using a binary criteria $(0,1)$, recoded into three categories for the regression analysis (high, medium, low) (see data sources in Figure 2). It 
includes prescriptions of accountability (specialized commissions, hearings and audits, free access to information about municipal actions, and free expression in council meetings). Second, a rate index is based on available prescriptions of municipal internal organization using a binary criteria $(0,1)$, also recoded as high, medium, and low (see data sources in Figure 2). This variable quantifies information on institutionalized planning, operational rules of management (e.g., performance agreements, incentives, evaluations), coordination, and integration (e.g., land planning, DRR, adaptation, environment, infrastructure). Third, compliance with standards of transparency consists of data on municipal compliance with normative prescriptions [178]. Accountable municipal councils, robustness of municipal organization, and transparency may enhance the effects of variables representing capacities and political leadership attributes on Investment [3,16,22,55,129-131,183,184].

Resource transfers. In Chile, financial transfers from national to local governments represent institutional incentives created by governance relationships $[3,51,58,180]$. During the period 2009-2016, the sampled municipalities received monetary funds from ministries $[48,179,185]$ (see data sources in Figure 2). The transfer variables to improve urban infrastructure equipment measure annual per capita monetary transfers from the Undersecretary of Ministry of Interior and Public Safety (SUBDERE) aimed at improving local infrastructure $[186,187]$. We expected moderating effects of those transfers on the relationships between capacities, leadership, and local government decisions $[1,3,6,12-14,43,100,105,132,133,145-148,188]$.

Control variables. The control variables measure attributes of location, climate, population, socioeconomic fragilities and deprivation in infrastructure, extreme weather events and disasters, and financial and territorial administration $[45,47,48,57,68,69,73,75,76,79,80,169,171-174]$. We followed the control function approach to alleviate endogeneity concerns [40]. All random effect Tobit regressions included a rich set of 17 mutually uncorrelated exogeneous controls at municipal level along with time dummies at the year level, regional dummies, and capital city dummies (see description of variables in Figure 3). In this study, the control variables captured unobserved heterogeneity that might be associated with some of our target variables (endogeneity).

\subsubsection{Data Collection and Analysis}

The data collection and analysis consisted of the following seps: first, model specification, operationalization of concepts, and selection of metrics to explore evidence around hypotheses; second, data collection in official sources with available information and by request; third, population of databases, normalization of variables, recoding, and observation of central tendency measures; fourth, application of criteria for variable selection, i.e., accuracy of available data, validation by academic workshops, and consults with experts [56] (see data sources in Figures 2 and 5); fifth, we controlled for time and spatial effects along with other variables to provide a consistent estimation of conditional effects [39,40]; sixth, when defining the set of controls, we checked for imperfect multicollinearity and selected those with a large amount of independent variance; seventh, programming in STATA No. 16 using XTTobit command according to the model specification and expert-recommended procedures [189] (see xttobit command syntaxis in Appendix C); eighth, the standard errors of marginal effects were computed using the Delta method [153,190]; ninth, analysis of the regression model coefficients interpreting marginal changes in the dependent and independent variables, taking into consideration the fitness of the models; and tenth, selection of standard deviation and median as metrics to compare and discuss the results [191,192]. 
Nine illustrative cases, data and sources

-Annual public accounts of the mayors, 2009-2016 a

- Community development plans, 2009-2016 a

-Meeting minutes of municipal councils, 2009-2016 a

-Municipal budgets. 2009-2016 a

-Investments 2009-2016 a

- Transfers 2009-2016 a

-Staff 2009-2016 a, b

- Regulatory framework ${ }^{\mathrm{a}, \mathrm{b}}$

- Resolutions with Effects on Third Parties 2009-2016 a

- Electoral data a

-Transparency and accountability, audit reports a, b

-Environment data ${ }^{\mathrm{a}, \mathrm{b}}$

-Geospatial Data Infrastructure a

-Population, interpolation 1930-2017 a

- Socioeconomic characterization surveys and data a

-Quality of life surveys a

-Environment surveys ${ }^{\text {a }}$

-Underlying risk factors database $\mathrm{a}, \mathrm{b}$

- Extreme weather events and disasters, data a, b

-Semi-structured interviews, municipalities $(45)^{\mathrm{b}}$

-Discussion groups and workshops, public officials and researchers $(20 \text { [56] })^{\mathrm{c}}$

- Technical interviews, experts ${ }^{c}$

- Citizen satisfaction and trust 2009-2016 a,c

Figure 5. Illustrative cases, context. ${ }^{a}$ Reliable data from public sources with available information $[45-48,52,53,56,63,66,68-$ 70,73-76,79-83,167-179,181,185,193-203]. ${ }^{\mathrm{b}}$ Directors of environment, civil protection and emergencies, planning, public works, and social organizations, five in each municipality. Chronological record of interviews: Cauquenes, March-June 2015, March-April 2016; Concepción, La Florida, Renca, and Valparaíso, December 2015-June 2016; Lebu, October-December 2016; Panguipulli, October 2014-January 2017; Osorno and Puerto Montt, March 2016-October 2018. ${ }^{\mathrm{c}}$ Discussion groups organized with municipal officials, academic seminars, and workshops with chronological record April 2014-January 2021.

\subsection{Qualitative Analysis: Case Selection, Data Collection, and Analysis}

\subsubsection{Case Selection}

To analyze the quantitative findings with documented experiences in municipalities, we employed interviews applied in municipalities of territories with populations at risk regarding lack of critical infrastructure and similar geographical, social, economic, and environmental conditions, such as exposure due to their locations, climate change, natural resource dependency, accelerated urbanization, socioeconomic fragility, high environmental risk perception, and frequency of natural disasters [47,48,52,53,63,69,73-76] (Figure 4). The interviews were applied to a representative sample of 98 selected cases located in the central south of the country, where $90 \%$ of the country's population lives, composed of rural and urban communities, 44 with populations greater than 70,000 and 58 between 3000 and 70,000. Geographical selection criteria included location in coast, valley, or mountain (Figure 1), and disaster criteria were hydrometeorological, geophysical, biological, environmental, and technological with socioeconomic fragilities and need for more infrastructure $[4,5,45,47,52-55,57,61,68-70,73-76,79-81,83,167-175,185]$.

To compare in depth and improve the quality of the study results, we selected a subsample of representative cases. We considered potential limitations in the selection of the 
cases, because all Chilean municipal territories are different (surface, population, culture, economy). Guided by our research question, the hypotheses, and the need to identify cases that could contribute to understanding the findings of the quantitative analysis, we decided to apply the recognized difference criteria method suggested by John Stuart Mill to identify cases that allowed us to document and compare the effects of institutional variables. In other words, we selected the cases based on variations in the institutional variables of interest, without regard for the dependent variables. We agreed on criteria to prioritize selection of municipalities with similarities from the perspective of exposure and vulnerability, on one hand, and differences in relation to how local governments contribute to adaptation through investments in critical infrastructure, on the other.

We identified municipalities with similarities (e.g., challenging environmental conditions, socioeconomic indicators) but contrasting outcomes related to local government decisions in Investment and selected nine illustrative cases: Valparaíso in Valparaiso region ( $\left.33^{\circ} 02^{\prime} \mathrm{S} 71^{\circ} 37^{\prime} \mathrm{W}\right)$, La Florida and Renca in Metropolitan region $\left(33^{\circ} 33^{\prime} \mathrm{S} 70^{\circ} 34^{\prime} \mathrm{W}\right.$ and $33^{\circ} 24^{\prime} \mathrm{S} 70^{\circ} 44^{\prime} \mathrm{W}$ ), Cauquenes in Maule region $\left(35^{\circ} 58^{\prime} \mathrm{S} 72^{\circ} 18^{\prime} \mathrm{W}\right)$, Concepción and Lebu in Biobio region ( $\left.36^{\circ} 49^{\prime} \mathrm{S} 73^{\circ} 03^{\prime} \mathrm{W}\right)$, Panguipulli in Los Rios region $\left(39^{\circ} 38^{\prime} \mathrm{S}\right.$ $72^{\circ} 20^{\prime} \mathrm{W}$ ), Osorno and Puerto Montt in Los Lagos region $\left(40^{\circ} 34^{\prime} \mathrm{S} 73^{\circ} 09^{\prime} \mathrm{W}\right.$ and $41^{\circ} 28^{\prime} \mathrm{S}$ $72^{\circ} 56^{\prime} \mathrm{W}$ ). The cases represent communities experiencing accelerated urbanization processes, socioeconomic fragilities, populations living at risk, and deprivation in infrastructure $[47,52,53,181,193-201]$.

The nine communities were in need of more Investment, but the local governments contrasted in engagement and performance, as well as in citizen satisfaction with the municipalities [3,52,54,55,82,185,194-202]. In the weekly council meetings during 2009-2016, the local governments of Concepción, La Florida, Osorno, and Panguipulli discussed Investment projects (new critical infrastructure) 93 times per year on average, executed an average of 69 projects per year ( $40 \%$ of the total), invested an average of 2,205,149 USD of the budgetary resources in new infrastructure, and used 3404 USD per capita transferred by Undersecretary of Ministry of Interior (SUBDERE) and regional governments as complements to municipal monies [195,196,198,199]. Contrasting those cases, Cauquenes, Lebu, Renca, Valparaíso, and Puerto Montt discussed Investments with lower frequency (annual average of 29 times), executed only an average of 21 projects yearly ( $30 \%$ of the total), invested 547,330 USD municipal resources per year, and used the transferences of 775 USD per capita for the execution of tasks designed by national and regional programs in Maintenance [194,197,200,201].

Regarding social outcome perceptions, available data suggest that the citizens of Concepción, La Florida, Osorno, and Panguipulli manifested higher evaluations of municipal services, effectiveness of their local governments, and trust $[3,52,185]$ (Figure 5).

\subsubsection{Data Collection and Analysis}

To provide robustness to the results of the quantitative analysis with documented experiences in municipalities, we used survey results from face-to-face, semi-structured interviews with directors of civil protection and emergencies of 98 municipalities in nine regions between April 2015 and December 2016, Figure 4. Other primary sources and databases were consulted to obtain additional information $[47,48,52,53,57,63,66,69,73,75$, 76,80-83,157,158,162,163,167-171,176,177,198,199].

The qualitative analysis included in the study is based on a rigorous procedure to select and process information from primary sources (Appendix D). The data on the nine illustrative cases were collected from several sources, i.e., interviews with municipal officials, primary sources, and official data $[47,48,53,66,68-70,73-76,79-83,167-172,177-$ 179,181,185,193,203] (Figure 5).

The collected information was organized in databases to produce inputs for the analysis. A database populated with the survey data and complementary information gathered from primary sources provided inputs to produce documented observations on the 98 municipalities employing the Program SPSS 23. To go deeper into the discussion of 
the quantitative results through contextualized analysis, the data collected from interviews, official records, and statistical sources were triangulated to compare among the nine illustrative cases, combining content analysis and descriptive statistical data analysis (Appendix D). These comparisons complemented the quantitative inferences.

The evidence demonstrated that the institutional dynamics and factors we found to be the most important were consistent with those found in the quantitative analyses (e.g., municipal organization robustness and accountability variables, political leadership attributes), allowing the qualitative analysis to provide more complete insights about the moderation mechanisms and processes at work.

In sum, using these procedures, we produced knowledge that fills the gap in previous research around the explanation of how capacities and political motivation translate to local government decisions.

\subsection{Validity}

The data for the research were collected in Chile for an in-depth study of Chile and local governments there. The possible disadvantage is that the specific results cannot be fully extrapolated to other places. We tried to reduce the effects of the disadvantages by formulating a research problem, questions, and hypotheses that are relevant in the literature on the subject and valid for research activities elsewhere [3,13]. In fact, we reviewed theories and literature on disaster risk reduction, adaptation, local governments, theories of organizations, and multilevel governance. Likewise, we were careful in the selection and operationalization of the concepts and the selection of metrics for the analyses, expecting that they could be employed by other studies in other cases, for example municipal investments (continuous variable), municipal regulations (index), and government transfers (continuous).

Although a possible disadvantage is that the specific results cannot be fully extrapolated to other places, the findings carry some validity for other low- and middle-income countries that are affected by exposure to frequent natural disasters, climate change, and vulnerability, and that urgently require more investment in critical infrastructure. One should be careful, however, in drawing too many parallels from our study's findings to these other contexts. That said, the similarities, succinctly documented in the review by the Working Group II to the Fifth Assessment Report of the Intergovernmental Panel on Climate Change [13], provide external validation for the results of the study. In South America, for example, the findings on the importance of municipal organization robustness are valid for countries such as Argentina, parts of Brazil, Colombia, Perú, or México, where communities need more investment and local governments perform functions similar to those of Chile. Even for countries on other continents with similar challenges, where local governments have responsibilities to fulfill and their decisions have consequences for the well-being of the population, the results of this study are also valid.

\section{Results: Quantitative Evidence and Analysis with Support of Qualitative Evidence}

This section outlines the evidence. The results from four models are reported in two output tables. Table 1 presents models 1 and 2 with marginal effects of variables that represent capacities, political leadership attributes, and moderating effects of the autonomy of the municipal councils on the outcomes (model 1, Investment; model 2, Maintenance). Table 2 shows the moderating effects of the resource transfers variable "subdeinvesttrans" (models 3 and 4). The effects of the control variables are not outlined in Tables 1 and 2 in order to focus on direct and moderated effects of independent variables on dependent variables. 
Table 1. Effects of capacities, leadership, and accountability as moderator.

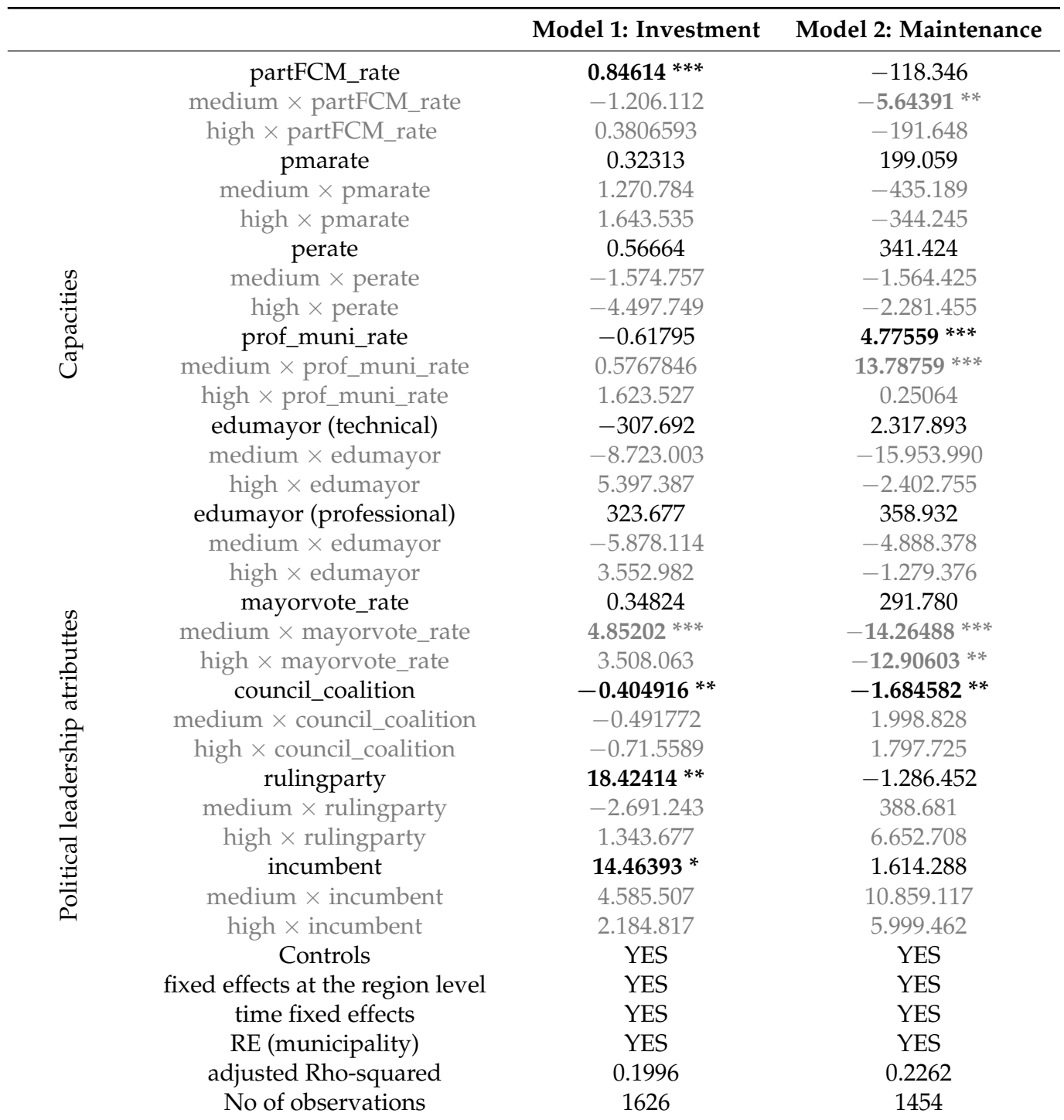

${ }^{*} 10 \%,{ }^{* *} 5 \%,{ }^{* * *} 1 \%$ significance level. Note: The variables in gray are combinations of the variable municipal council accountability with the respective independent variables (e.g., municipal capacity and political leadership attributes variables).

Table 2. Effects of capacities, leadership, and resource transfers as moderators.

\begin{tabular}{lcc}
\hline \multicolumn{1}{c}{ Variables } & Model 2: Investment & Model 3: Maintenance \\
\hline partFCM_rate & $\mathbf{0 . 9 5 6 1 1} * * *$ & $\mathbf{- 2 . 0 3 5 2 1} *$ \\
interaction $\times$ partFCM_rate & 0.00469 & $-0.14008^{* * *}$ \\
pmarate & -220.363 & -1.157 .431 \\
interaction $\times$ pmarate & -0.07790 & $-0.49204^{*}$ \\
perate & -0.21570 & 816.279 \\
interaction $\times$ perate & 2.080 .444 & $0.35228 * *$ \\
prof_muni_rate & -0.61014 & $\mathbf{4 . 3 8 7 9 5} * *$ \\
interaction $\times$ prof_muni_rate & -0.00315 & $0.12606^{* * *}$ \\
edumayor (technical) & 234.609 & -1.615 .647 \\
interaction $\times$ edumayor & -0.842372 & -0.20869 \\
edumayor (professional) & $-\mathbf{0 . 8 4 2 3 7 2 * * *}$ & -2.322 .270 \\
\hline
\end{tabular}


Table 2. Cont.

\begin{tabular}{|c|c|c|}
\hline Variables & Model 2: Investment & Model 3: Maintenance \\
\hline interaction $\times$ edumayor & $-1.214724 * * *$ & -0.15584 \\
\hline mayorvote_rate & 0.30316 & $4.21960 * *$ \\
\hline interaction $\times$ mayorvote_rate & $-0.01622 *$ & 0.02872 \\
\hline council_coalition & $-0.529106^{* * *}$ & $-1.577342 * *$ \\
\hline interaction $\times$ council_coalition & $-0.010583 * * *$ & $-0.357629 * *$ \\
\hline rulingparty & $16.70460 * *$ & -2.807 .512 \\
\hline interaction $\times$ rulingparty & -0.2678327 & $-1.91807^{* * *}$ \\
\hline incumbent & $22.44683 * * *$ & 2.661 .684 \\
\hline interaction $\times$ incumbent & $1.113316 * * *$ & $3.38906 * * *$ \\
\hline control & YES & YES \\
\hline $\begin{array}{l}\text { fixed effects at the region level (15 } \\
\text { regions) }\end{array}$ & YES & YES \\
\hline time fixed effects & YES & YES \\
\hline RE (municipality) & YES & YES \\
\hline adjusted Rho-squared & 0.2349 & 0.2543 \\
\hline No of observations & 1626 & 1454 \\
\hline
\end{tabular}

${ }^{*} 10 \%,{ }^{* *} 5 \%,{ }^{* * *} 1 \%$ significance level. Note: The variables in gray are combinations of the resource transfer variable "subdeinvesttrans" with the respective independent variables (e.g., municipal capacity and political leadership attributes variables).

\subsection{Regressions, Marginal Effects, Standard Deviation, and Median}

The results of the regression models support the Alternative Hypotheses on moderating effects of municipal organization and governance relationships in terms of resource transfers.

Beginning with the direct and independent effects of capacity variables, we hypothetisized that financial and human resources are always key factors for Investment (Null Hypothesis 1). Table 1 shows that municipalities more dependent on the Municipal Common Fund (partFCM_rate variable) increase Investment and municipalities with more professional employees put more money into Maintenance. On one hand, $1 \%$ annual increase in dependence on the MCF is associated with an annual extra investment of 846 CLP per inhabitant, i.e., a municipality one standard deviation more dependent on MCF compared to the average of the sample increases Investment annually $12 \%$. On the other hand, $1 \%$ increase in the number of professional staff predicts an increase in Maintenance of 4776 CLP per inhabitant or $20 \%$ more in Maintenance than the average municipality.

When we shifted attention to the direct and independent effects of leadership variables, we hypothetisized that political leadership attributes in its own right represents another key factor for Investment (Null Hypothesis 2). Table 1 indicates, first, where mayoral support from the municipal council in terms of political coalition representation increases by $1 \%$, annual Investment decreases by 405 CLP per inhabitant, and annual Maintenance decreases. If mayoral coalition representation is one standard deviation higher than the average, we expect Investment in this municipality to decrease by $7 \%$. Second, if the mayor and the national president are in the same political coalition, annual Investment increases by 18,424 CLP (13\%) per inhabitant. Third, when the mayor is in his or her second term or more, annual investment increases by 14,464 CLP (10.4\%) per inhabitant.

As stated in Alternative Hypothesis 1, the relationship between capacities and Investment (Maintenance) is moderated by municipal organization processes. Using the municipal council autonomy variable (iacm), that in our framework expresses accountability, model 2 (Table 1) reveals that the local government receiving more financial resources from the MCF expends less on Maintenance when the municipal council manifests more autonomy $(48 \%)$. However, where a municipality has one standard deviation more professional employees and more municipal council authonomy, Maintenance increases by $58.7 \%$.

Looking at complementary specifications, using the municipal organization variable "orgm" as the moderator (e.g., municipal organization with planning, performance agreements, interdepartmental coordination, integration), models 5 and 6 (Table A5) result in a 
$1 \%$ increase in the dependence on the MCF associated with an 8484 CLP per inhabitant rise in Investment when the municipal organization is highly robust (122\%).

With respect to the hypothesized moderating effect of the municipal organizational dimension on the relationship between political leadership attributes and Investment (Alternative Hypothesis 2), the mayor's electoral support becomes statistically significant when it is moderated by a higher level of council autonomy, models 1 and 2 (Table 1). Each extra percentage point of the mayor's winning votes is associated with increased Investment where the municipal council shows more autonomy (35\%). Model 5 (Table A5) also shows that an extra percentage point in the mayor's electoral support is associated with 38,268 CLP increase in Investment when the organization is more robust. If the mayor was elected with one standard deviation more votes than the average, we expected that municipalities with higher organizational robustness will increase Investment by $160 \%$.

The fitted models reported in Table 1 explain $20 \%$ of the observed heterogeneity in the output variables.

Table 2 displays model estimates of capacities, political leadership atributtes, and moderating effects of resource transfers.

Returning to the Null Hypothesis 1, Table 2 shows that the direct and independent effects of capacity variables on Investment and Maintenance decision outcomes generally align with the effects reported in Table 1 in terms of direction and magnitude. Centering the attention on the direct effects of political leadership attributes variables on Investment and Maintenance decisions (Null Hypothesis 2), the results in Table 2 again exhibit strong consistency with the models reported in Table 1. Nevertheless, in model 4, a new effect emerges. One percent increase in a mayor's voting support increases Maintenance by 4220 CLP, i.e., if a mayor's electoral support is one standard deviation larger than the average, we expect Maintenance to increase by 42,200 CLP (18\%).

With respect to the Alternative Hypothesis 1, i.e., moderating influence of resource transfers interacting with capacity variables, if transfers increase by 1000 CLP per inhabitant, Investment decreases by 1215 CLP per inhabitant, where local governments are led by mayors with tertiary education (compared to those whose mayors do not have bachelor's degrees). If we double the amount of median transfers that municipalities receive, Investment decreases by 14,580 CLP (10.5\%) in municipalities led by mayors with tertiary education. Regarding Maintenance, a 1000 CLP increase in transfers is associated with a decrease in Maintenance by 140 CLP, where a municipality is $1 \%$ more financially dependent on the MCF, and by 492 CLP where staff connected to environment-related activities increases by $1 \%$. If we double the median transfers in municipalities that have one standard deviation more workers of this type, Maintenance decreases by 29,520 CLP $(12.5 \%)$ with respect to the average Maintenance in our sample. The increase in transfer is also connected to an increase in Maintenance by 352 CLP where the personnel working on civil protection and emergency-related activities increase by $1 \%$. If we double the median transfers in a municipality that has one standard deviation more workers in this category, Maintenance increases by 12,672 CLP (9\%). The increase in transfers induces further increase in Maintenance by 126 CLP for each additional percentage point of professional employees working for the municipality.

With regard to the moderating consequences of transfers on political leadership attributes (Alternative Hypothesis 2), models 3 and 4 indicate the following effects. First, each extra percentage point of a mayor's winning votes in the election interacting with more transfers decreases Investment by 16.2 CLP (1.4\%). Second, for each additional percentage of mayoral political representation in the municipal council (same political coalition) and increase of transfers, Investment decreases by 10.5 CLP (2.2\%) and Maintenance by 358 CLP (43\%). Third, Maintenance decreases by 1918 CLP (9.7\%) in municipalities where the mayor is in the same party coalition as Chile's president and that receives more transfers. Fourth, Investment increases by 1113 CLP (9.6\%) and Maintenance by 3389 CLP (17.3\%) in municipalities with mayors that are in their second term or more and that receive more transfers. 
The overall fitting of the models is $23.5 \%$ for Investment and $25.4 \%$ for Maintenance.

\subsection{Analysis of the Findings with Support of Qualitative Evidence}

Based on estimated models (Tables 1 and 2, Tables A3-A5), we put confidence in Alternative Hypotheses 1 and 2 about moderation effects on the outcomes. The evidence suggests that there are conditional effects of capacities and political leadership attributes variables of mayors on local government decisions and their outcomes, and that municipal organization variables and incentives of the resource transfers seem to moderate the effects of those variables. The variables that represent the political qualities of leadership appear quantitatively more important than the municipal capacity variables to explain Investment. The municipal organization variables have the most quantitatively important moderating effect in some capacity and leadership variables. The resource transfers variables moderate a larger number of variables, but they do not have so much impact.

\subsubsection{Financial Resources, Professional Staff, Political Leadership Atributtes}

Concerning direct and independent effects, two capacity variables are particularly relevant to explain local government decisions in Investment and Maintenance: MCF and professional staff.

Chilean municipalities more dependent on financial resources from the MCF invest more in resilient critical infrastructure, approximately $12 \%$ more than the average. We interpret the result as desirable and positive, because most of the communities need more resilient infrastructure to reduce socioeconomic fragilities, deprivation in infrastructure, and address the challenging environmental conditions [3,48,51-53,56].

Consistent with theories of internal organization and findings by sustainable cities $[1-3,72,89,90,94]$, the evidence from Chile suggests that municipal professional staff is devoted to executing managerial tasks in Maintenance rather than working on planning and Investment. The behavior of Chilean public servants is shaped partly by the weight of the inherited legalistic tradition $[51,185]$, reinforced by Chilean governments during the last four decades $[48,50,184,187,204,205]$. The Chilean legislation prescribes continuity for most municipal employees, depending on the performance of encoded and monitored functions, and most of the municipal professionals make their careers within the same municipality [204]. Furthermore, the municipalities must fulfill shared functions with several public organizations; therefore, municipal workers are usually stressed trying to fulfill several objectives in Maintenance at the same time, with overlapping functions and often contradictory goals [51].

In the survey applied to the sample of 98 municipalities, $83 \%$ of professional officials reported compliance with what is indicated by law and by higher senior authorities [56]. Regarding the nine illustrative case studies, the available council meeting minutes document recurrent behaviors of senior professional officials during 2009-2016: commitment and evaluations according to encoded norms that justified the prioritization of efforts on Maintenance in council meetings and study commissions [194-202]. Some interviewed officials confirmed that Maintenance is part of the essential functions of the municipalities, encoded in norms (Figure 5). In sum, encoded prescriptions and administrative procedures, linked to the inherited centralized legal framework, operational rules, and probably other conditions such as managerial organization goals, stability, and promotion, explain conservative behaviors by the municipal professionals, prone to favoring the status quo in managerial Maintenance.

With respect to political leadership attributes, the literature proposes relationships between electoral behavior, local government decisions, and outcomes [41,103,118]. In Chile, the electoral support for mayors is associated with more Maintenance. However, the evidence from different assessments, studies, and surveys report that most of the communities are in need of Investment [51-53,56,59-61]. In the survey and in interviews during the research of this study, on average, mayors declared their commitment to more Investment $[3,56]$ (see sources in Figure 4). In five of the nine illustrative cases (La Florida, 
Concepción, Osorno, Panguipulli, Valparaíso), most of the interventions of mayors in weekly municipal council meetings focused on new Investments [195,196,198,199].

The reasons for the apparent paradox have to do with the institutional context and incentives. The mayors with electoral support must show concrete results in Investment during their four-year period of governance or, if it is not possible, in Maintenance. Their decisions are contingent on several factors that are not always under their control. For example, the earthquake of February 2010 (magnitude 8.9) determined the priorities of the local governments in Concepción, Cauquenes, and Lebu for one year [194,195,197], and financial problems inherited from past administrations became decisive in the budgetary decisions of other municipalities [194,200].

The literature reports that municipal council support affects local government outcomes in the emerging policy domain such as planning $[2,3,35,36,89]$. In Chile, the mayoral political coalition representation in municipal councils decreased Investment. This result reveals links between local politics and outcomes in the following dimensions. First, political electoral competition in Chile began to be highly polarized in the first half of the 2010s [206]; local politicians tended to prioritize expenditures on issues guided by political compromises and electoral calculation $[4,61,207]$. Second, the combination of mayoral personalized administration and lack of political competition (balance) fostered laziness within the local government, weakening accountability [163]. The documented routines in municipal council meetings of the nine illustrative cases provide evidence of those dynamics $[4,54,55,61,194,197,200-202]$ : compromises in municipal councils with agendas where Investment was not thematized in Renca, Cauquenes, Lebu, Valparaíso, and Puerto Montt. In the cases of Concepción, La Florida, Osorno, and Panguipulli, where the councils were politically divided, councilors manifested awareness of their prerogatives and pressured for more performance in Investment [55,61,157,195,196,198,199].

The literature of sustainable cities reports that the continuity of decision makers is relevant in emerging policy domains, for example, the first stages of adaptation planning [2,3,35]. The evidence of Chile consistently shows that incumbency of the mayor increases Investment. The achievement of Investment projects may take years because the preparation requires several studies and procedures [82]. The experiences of four illustrative cases (Concepción, La Forida, Osorno, and Panguipulli) of the municipalities with higher Investment show that continuity was relevant [55,195,196,198,199].

According to the literature review, political support at other scales of governance may open opportunities to advance in emerging local government agendas $[3,36,98,102,103]$. In Chile, the regressions consistently show that closeness of the mayor to the ruling party increases the likelihood of Investment. For instance, the mayor of La Florida belonged to the ruling party in the center-right government of President S. Piñera (2010-2013) and the political support facilitated access to technical and financial aid to carry out important projects for the community [196]. Investment also increased during the second term because access had been established via experience and political association.

\subsubsection{Municipal Organizational Arrangements}

The reviewed theories and experiences in sustainable cities suggest that some attributes of municipal organization create differences between local governments in adaptation planning $[1-3,13]$. In Chile, the municipal organization robustness presents the most quantitatively important moderation effect. For example, the largest moderating effect on the relationship between mayor electoral support and Investment $(160 \%)$ is driven by the level of robustness in municipal organization in view of internal regulations, planning, coordination, and integration. Likewise, local governments that receive more financial resources from the MCF and have high municipal organizational robustness invest more (122\%).

The results of the survey further indicate that 25 municipalities $(25 \%)$ with plans for DRR and climate change adaptation reported more engagement than the average of the sample in activities related to DRR, climate change adaptation, and infrastructure Investment, while 43 municipalities (44\%) without planning were below the average [56]. 
In 57 municipalities with more organizational robustness than the average, civil protection and emergency directors participated in activities related to infrastructure investment, whereas directors did so only in nine municipalities of the group with a lower degree of robustness. A comparison of illustrative cases shows how these interactions operated. In Panguipulli, Osorno, La Florida, and Concepción, DRR, environmental protection, and infrastructure planning were highly institutionalized, with collaboration between departments and more integration than in other cases $[4,16,54,55,61,195,196,198-200]$. From the mid-2000s, the local governments of those four municipalities introduced reforms in the municipal organization, such as internal regulations to improve management, institutionalization of departments for risk management and environmental protection, and plans with performance agreements and monitoring systems [55,61,195,196,198,199]. These changes incentivized increased awareness and engagement regarding citizens' needs, risk reduction, goal improvements, organizational reoutines, and new investments.

For example, the local government of La Florida introduced planning and macrological procedures in all departments, more coordination and integration, and accountability in the routines of each unit [196]. At the same time, La Florida invested in GIS technologies and training to improve information flow on territorial issues and interdepartmental integration. Planning, coordination, integration, and access to accurate information optimized municipal activities, and facilitated the execution of several projects in road infrastructure and urban improvement during 2009-2016. In Concepción and Panguipulli, we observed similar paths $[55,61,195,198,199]$. In a clear divergence, Puerto Montt, Valparaíso, and Renca lacked planning, operated departments in isolation, conditioned assessments and government decisions to the discretion of mayors, senior officials, and councils who did not prioritize Investment, and had contrasting outcomes [4,16,54,55,61,200-202].

The juxtaposition of cases also shows how organizational robustness moderates other factors. For example, in La Florida, the opportunities for investments depended not only on the motivation and electoral support, but on municipal organization robustness to perform in terms of recurrent routines (prioritizing the subject, management, assessments, studies, applications, and execution) [196]. Furthermore, the implementation of the institutionalized plans (e.g., community development, DRR, infrastructure) and the robustness of the municipal organization yielded additional funds from the MCF for Investment $[185,196]$. The consequence of viogorous municipal organization, mayoral electoral support, and transfers was an exponential leap in Investment after 2011, higher when compared to the previous period and other municipalities [196]. The trajectories of Cauquenes, Lebu, Puerto Montt, Renca, and Valparaíso reveal clear contrasts, i.e., municipal plans that declared goals, not having scheduled and responsible execution or performance agreements, contradictory operational rules, personalized administrations, municipal departments working as silos, civil and environmental protection units marginalized within organizations, frequent administrative problems affecting efficiency in outcomes, and low Investment [194,196,197,200-202].

The reviewed literature suggests that accountability practices are important organizational attributes for performance with equitable provision of public goods $[3,41,55,130,131,148,159]$. In the regression models, municipal council accountability becomes quantitatively relevant in positively moderating the effect of mayoral electoral support for Investment. Municipalities with higher municipal council accountability governed by mayors with high electoral support invested 35\% more than the average of local governments.

In Chile, the grade for municipal council accountability is contingent on municipal institutional arrangements such as internal regulations and displayed by weekly council meetings and study commissions $[3,55]$. As policy makers, the councilors are in position to provide valuable information, disseminating awareness on issues, introducing frameworks, deliberation, and voting. In Concepción, La Florida, Osorno, and Panguipulli, municipal councils with high degrees of accountability granted by internal regulations proactively supported Investments (e.g., disseminating awareness, requesting information, assessments, and proposing projects to improve infrastructure) $[4,16,54,55,61,196,198,199]$. By 
contrast, the municipal institutional arrangements of Cauquenes, Puerto Montt, Renca, and Valparaíso restricted their municipal councils' autonomy [194,200-202].

\subsubsection{External Institutional Dynamics (e.g., Governance Relationships)}

With reference to governance relationships, international frameworks in the literature and one part of the literature on sustainable cities propose multilevel interactions as key to progress in emerging policy domains at the local level $[3,5-7,12-14,43]$. In Chilean municipalities, these dynamics moderate a large number of capacities and political leadership attributes variables, but they have less impact from a quantitative point of view. For example, the national government transfers did not affect the path of the professionals. In some cases, such as Cauquenes, Lebu, and Puerto Montt, those transfers introduced more incentives for Maintenance, because the professionals wanted to devote more time or effort to doing their jobs better, rather than start new projects in uncharted territory $[4,55,61]$.

\section{Conclusions}

In the conclusion, we summarize some of the challenges of our study "Causes and Consequences of Local Government Efforts to Reduce Risk and Adapt to Extreme Weather Events: Municipal Organizational Robustness" in terms of results, achievements, advances in relation to previous studies, relevance, contributions, problems and possibilities in generalizing, limitations, and practical implications.

Seeking to enhance understanding of how organizational capacities and political dimensions of mayoral leadership are translated into decisions, this study realized as a starting point that capacities and underpinning factors for mayoral leadership (electoral, municipal council, political support, and continuity) may explain local government decisions concerning Investment. However, from another point of view, we hypothesized that institutional dynamics (e.g., municipal organizational arrangements and governance relationships) take part as moderators in the complex configuration of factors that connect capacities, political leadership attributes, and outcomes. With collected data from 345 typical Chilean municipalities, we explored those hypotheses, emerging conditional relationships between capacities, the leadership attributes, and outcome variables. Both quantitative evidence and analysis supported by qualitative evidence indicate the relevance of interactions between municipal institutional arrangements, capacities, leadership attributes, and outcomes, and, therefore, the relevant roles of organizational robustness, and accountability. The evidence supports our Alternative Hypotheses 1 and 2, insofar as the relationships between explanans and explanandum are conditioned by moderating variables. Hence, we conclude that the connection between political leadership attributes, capacities, and Investment in Chile depend to a large degree on the municipal robustness in terms of operational rules, planning, coordination, integration, and accountability.

With respect to achievements, the research conducted led to an explanation about how capacities and leadership translate to local government decisions and outcomes regarding adaptation in terms of critical infrastructure. The study fills a gap in the literature through analysis of theories, case studies, a suitable model specification, methodological design with mixed methods, results, and a deeper discussion of the evidence. Similar to earlier researchers, we already knew the relevance that several factors might have to local adaptation, such as capacities, leadership, framing, intergovernmental relations, data and assessment, and social participation; for example, financial resources or leadership motivation were important, but we did not know the relative importance or the institutional mechanisms that work to make those factors effective and relevant. Now, we have knowledge and the opportunity actually to increase the effects of capacities and leadership by improving the municipal organizational robustness. Since one of the objectives of the Special Issue "Bringing Governance Back Home-Lessons for Local Government Regarding Rapid Climate Action" is to explore how action is enabled or constrained by institutional relations in which the actors are embedded, this study contributes to achieving that goal. 
The explanation about causes and consequences of municipal institutional arrangements is the study's most important contribution to the areas of DRR, climate change adaptation, and sustainability science. As for possibilities for future research in this respect, greater integration of conceptual frameworks, theories, research methods, and evidence-based knowledge on the subject will facilitate suitable recommendations for local decision makers, increasing the likelihood that political leaders will contribute to pursuing sustainability.

In terms of contributions to theoretical areas, the Chilean experience teaches us that performance is not granted by capacities or leadership motivation per se. Mayors, as political leaders and decision makers motivated or not by adaptation, make decisions based on features of the organizational systems in which they are embedded. We expect that any improvement in the municipal organizational system increases the probability of moving forward from leadership motivation to results. Hence, we conclude that whenever there is balance from the point of view of municipal political-administrative configuration (e.g., mayors with electoral support and powers to administer the municipality, organizational robustness, and councilors with the ability to enforce accountability), the probability to advance with local government decisions in the emerging policy domain of adaptation becomes greater. This conclusion implies that where more investment in resilient critical infrastructure is required, organizational robustness and accountability are essential ingredients to achieve progress, making it possible for capacities and political will to translate into decisions and actions.

Other countries have similar problems with respect to frequent disasters and negative effects of climatic change, for example neighboring countries. Specific risks might be different there, but their struggles with local climate change adaptation are similar enough that we expect our results in Chile to be relevant for their local government decision-making. In Asian and African countries where the threats are not too different from Chile's, our results may also be relevant. Our findings about moderating effects and relationships are potentially useful there, as well as the concepts that municipal organization and political support are big factors to see concrete results.

Regarding limitations, one issue of our research was the lack of accurate information and data before 2009. We would have liked to do a longer study in terms of years covered, but it was impossible to find accurate official data due to lack of transparency in national legislation pre-2009. Another limitation was the irregular quality of the data. To a certain degree, we overcame those limitations through the analytical operationalization of concepts, taking into consideration the availability of data, critical selection of metrics related to hypotheses, data collection from several sources with available information, requests for data for purposes of transparency, data normalization, observation of central tendency measures for the quantitative analysis, application of rigorous criteria for variable selection, accurate selection of control variables, rigorous selection of representative cases, and sources of information for the qualitative analysis, among others. A further limitation was related to our causal inferences-the strategy of using a "control function" is not perfect, and may have been a possible source of omitted variable bias. Even though the random effect Tobit model fits the sample data better than the standard linear model (e.g., it captures the fact that several local governments do not invest), we could not control by fixed effects using "within estimators." To alleviate this potential source of misinterpretation, we included a rich set of mutually uncorrelated exogeneous controls. In addition, we compared and analyzed the results of the partial test with an independent rigorous analysis of qualitative evidence.

Finally, we describe the study's practical implications more precisely as follows. First, the contribution to increased local government decisions on adaptation is the central importance of municipal organization robustness in terms of operational rules, communication and coordination, integration, accountability, and political support. Hence, we recommend enhancing municipal organizational robustness, because it will moderate capabilities, political support, and maybe other factors in the right direction. Second, because those factors 
contribute to translating capacities and motivating to local government decisions, we identify an opportunity actually to enhance efforts to reduce risk and adapt to extreme weather events. Third, monetary transfers coming from national and regional governments are undoubtedly desirable ingredients for a fertile adaptation, but not as cardinal as internal managerial robustness; therefore, the process is like a bottom-up public policy to reinforce robustness, which is more effective connecting capacities, motivation, and decisions than a top-down policy of transfers or other types of external interventions (e.g., external scientific community championing adaptation, structured social participation in the municipalities, governance networks exchanging information and frameworks). Fourth, international cooperation and national and regional public policies could target public resources and decrease the frustrations of practitioners more efficiently if they place more attention on bottom-up local government robustness, like municipal operational rules, internal coordination, integration and flexibility, or transparency and accountability, i.e., the support and money from outside will go much farther or will do a lot more good only if the local robustness is strong.

Author Contributions: K.P.A., P.N., and P.V., conceptualization, formulation of the overarching research goals and aims, title, abstract, introduction, literature review, framework, methodological design, results, discussion, conclusion, and references; P.N. and P.V., methodology and software; K.P.A., P.N., and P.V., validation; P.N. and P.V., formal analysis; K.P.A., P.N., and P.V., investigation; K.P.A. and P.V., resources; P.V., data curation; P.N., and P.V., writing-original draft preparation; K.P.A., P.N., and P.V., writing—review and editing; P.V., visualization; P.V., supervision; P.V., project administration; P.V., funding acquisition. All authors have read and agreed to the published version of the manuscript.

Funding: This research was funded by the National Fund for Scientific and Technological Development (FONDECYT), National Research Agency of Chile, grant number 1181282; National Science Foundation, grant numbers DEB-1114984, SMA-328688, SES-1757136, and DGE-1650115; the Belmont Forum, grant number T2S-789.

Institutional Review Board Statement: The research was conducted according to the guidelines of the Declaration of Helsinki, approved by the Institutional Bioethics and Biosafety Committee of the Universidad de los Lagos, Chile (dates: 20 April 2015; 12 April 2018), and the Human Research Ethics Committee of the Universidad Austral de Chile (date: 25 June 2020).

Informed Consent Statement: Informed consent was obtained from all subjects involved in the study (e.g., interviews, survey).

Data Availability Statement: We used the data of Figures 2-5, and Table A1, most of which are publicly available. For some analyses, we used our own datasets, which are available upon request.

Acknowledgments: P. Valdivieso acknowledges financial support from the National Fund for Scientific and Technological Development (FONDECYT), Grant \# 1181282. We appreciate useful comments received by anonymous referees and one unidentified guest editor of the Special Issue. We express our gratitude to twenty seven undergraduate and eleven graduate students ( $U$ Austral Los Ríos region, $U$ Concepción Biobio region, U Lagos Los Lagos and Metropolitan regions, U Chile Metropolitan region, UFRO and U Arturo Prat Araucanía region, U Viña del Mar Valparaíso region), twelve professional collaborators (National Institute of Statistics, National Office of Emergency Los Lagos, National Women's Service Valdivia, German School Santiago, U Arturo Prat, U Austral, U Concepción, U Chile, U Lagos Chile, UFRO), Demoscopica Opinion Studies Group, and J. Broderick (editorial assistance) for research support. We express gratitude also to senior officials of 98 Chilean municipalities who welcomed us, shared their time, and expertise with us. We also benefited from constructive comments on research steps, progresses, and drafts of the study by attendees of the 2018, 2019, 2020, and 2021 bimonthly Institutional Analysis Workshop "Institutional Drivers of Environmental Disaster Reduction Management: A Comparative Study of Local Government Decisions and Outcomes in Chile" (available at http:/ / www.gobernanzamedioambiental.cl/, accessed on 11 July 2021), Millennium Institute for Research in Market Failures and Public Policy workshops (U Chile, Chile), Midwest and Western Political Science Association annual conferences (Chicago, IL, USA; San Diego, CA, USA), World Congress of the International Political Science Association (Lisbon, Portugal), International Americanists Congress (U Salamanca, Spain), International Congress of Solid Waste Infrastructure 
(UAM, Peru), Risk Reduction and Sustainable Development Conference (U Concepción, Chile), and twenty workshops and discussion groups (U Austral de Chile, U Concepción, U Los Lagos).

Conflicts of Interest: The authors declare no conflict of interest.

\section{Appendix A}

Table A1. Descriptions of independent and control variables.

\begin{tabular}{|c|c|c|}
\hline Variable & Description & Measurement \\
\hline partFCM_rate & Municipal Common Fund in the total budget ${ }^{a}$ & Percentage \\
\hline Pmarate & Municipal staff working on the environment $\mathrm{a}, \mathrm{b}$ & Percentage \\
\hline Perate & Municipal staff working on civil protection ${ }^{\mathrm{a}, \mathrm{b}}$ & Percentage \\
\hline prof_muni_rate & Staff holding a bachelor's degree ${ }^{\text {a }}$ & Percentage \\
\hline edumayor (technical) & Mayor's education, up to technical a, b & 1 , up to technical education; 0 , otherwise \\
\hline edumayor (professional) & Mayor's education, college or more ${ }^{\mathrm{a}, \mathrm{b}}$ & 1 , college or more; 0 , otherwise \\
\hline mayorvote_rate & Mayor's winning votes in the election ${ }^{\text {a }}$ & Percentage \\
\hline council_coalition & Councilors in the political coalition of the mayor ${ }^{a}$ & \\
\hline Rulingparty & $\begin{array}{l}\text { Elected president in the political coalition of the } \\
\text { mayor }{ }^{\text {a }}\end{array}$ & $\begin{array}{c}\text { 1, mayor and president in the same } \\
\text { political coalition; } \\
\text { 0, otherwise }\end{array}$ \\
\hline Incumbent & Continuity in office $^{a}$ & $\begin{array}{l}1 \text {, mayor is in a continuing appointment; } \\
0, \text { otherwise }\end{array}$ \\
\hline Iacm & Municipal council accountability index ${ }^{a, b}$ & 0, low or base; 1, medium; 2 , high \\
\hline Orgm & Municipal organization index ${ }^{a, b}$ & \\
\hline transptotal_rate & Compliance with standards of transparency ${ }^{a}$ & Percentage \\
\hline Subdemanagtranshab & Transfers to improve management ${ }^{\text {a }}$ & $\begin{array}{c}\text { Thousands of annual Chilean pesos (CLP) } \\
\text { per inhabitant }\end{array}$ \\
\hline $\begin{array}{l}\text { Subdeinvesttranshab } \\
\text { gastranscor_reghab }\end{array}$ & $\begin{array}{l}\text { Transfers to improve urban equipment }{ }^{\mathrm{a}} \\
\text { Regional government transfers }\end{array}$ & \\
\hline horizontal_networkhab & Transfers to and from other municipalities ${ }^{a}$ & \\
\hline Coastline & Location on the Pacific coast ${ }^{a}$ & 1 , coast; 0 , otherwise \\
\hline valley-mountain & Location in valley or mountain ${ }^{a}$ & 1 , valley; 0 , otherwise \\
\hline Size & Surface ${ }^{a}$ & Square kilometers \\
\hline Rainfall & Rainfall, annual a & Millimeters \\
\hline Temperature & Temperature, annual average ${ }^{a}$ & Celsius degrees \\
\hline Density & Population divided by surface ${ }^{a}$ & Ratio \\
\hline ethnic_rate & Indigenous population ${ }^{a}$ & Percentage \\
\hline urb_rate & Population residing in urban areas ${ }^{a}$ & Percentage \\
\hline pover_rate & Poverty ${ }^{\mathrm{a}}$ & Percentage \\
\hline unemploy_rate & Householders reporting not having a job ${ }^{a}$ & \\
\hline no_illegal_settlements & Agglomerations with population living at risk $^{a}$ & Number \\
\hline $\begin{array}{l}\text { num_eve_clim_hig } \\
\text { num_eve_clim }\end{array}$ & $\begin{array}{l}\text { Extreme weather events and disasters } 1971-2014^{a} \\
\text { Decrees in areas of water scarcity } 2008-2016^{a, c}\end{array}$ & Number \\
\hline earqk10_scale & Earthquake 2010 intensity $^{a}$ & Mercalli scale \\
\hline earqk10_deaths & Earthquake 2010 deaths ${ }^{\text {a }}$ & Number \\
\hline Reported & Declarations of emergencies ${ }^{a, c}$ & \\
\hline num_plantacontrata & Municipal employees ${ }^{a, b}$ & Number \\
\hline cap_region & Distance from the regional capital a & Kilometers \\
\hline
\end{tabular}

${ }^{a}$ Reliable data from public sources with available information $[47,48,53,57,68,69,73,76,79,81,167-172,175,177-179,181,185,193] .{ }^{b}$ Municipal secretaries, planning offices by request, websites. ${ }^{c}$ General Water Office, Library of Congress, and Ministry of Agriculture by request. 


\section{Appendix B}

Table A2. Descriptive statistics of variables.

\begin{tabular}{|c|c|c|c|c|}
\hline Variable Name & Measure & Average & Median & Std. Dev. \\
\hline population & Number & 50,040 & 18,148 & 77,496 \\
\hline investment & $\begin{array}{c}\times 1000 \text { annual CLP per } \\
\text { inhabitant }\end{array}$ & 139.3 & 28.7 & 550.7 \\
\hline maintenance & $\begin{array}{c}\times 1000 \text { annual CLP per } \\
\text { inhabitant }\end{array}$ & 235.0 & 72.6 & 864.5 \\
\hline partFCM & Percentage & $47.3 \%$ & $49.7 \%$ & $20.1 \%$ \\
\hline num_plantacontrata & Number & 109 & 52 & 163 \\
\hline prof_muni_rate & Percentage & $27.3 \%$ & $25.9 \%$ & $10.4 \%$ \\
\hline pmarate & Percentage & $1.0 \%$ & $0.0 \%$ & $5.2 \%$ \\
\hline perate & Percentage & $0.7 \%$ & $0.0 \%$ & $3.4 \%$ \\
\hline \multirow{3}{*}{ edumayor } & $\begin{array}{l}0 \text {, Without tertiary } \\
\text { education (base) }\end{array}$ & $22 \%$ & - & - \\
\hline & 1, Technical education & $17 \%$ & - & - \\
\hline & 2, Professional education & $61 \%$ & - & - \\
\hline mayorvote_rate & Percentage & $49.8 \%$ & $49.5 \%$ & $10.0 \%$ \\
\hline council_coalition & Percentage & $30.8 \%$ & $33.3 \%$ & $23.9 \%$ \\
\hline rulingparty & $\begin{array}{c}\text { 1, Mayor and president in } \\
\text { the same political coalition; } \\
0 \text {, Otherwise }\end{array}$ & $37.5 \%$ & - & - \\
\hline \multirow[t]{2}{*}{ incumbent } & $\begin{array}{l}\text { 1, Mayor is in a continuing } \\
\text { appointment; } 0 \text {, Otherwise }\end{array}$ & $51.4 \%$ & - & - \\
\hline & 0, Low (Base) & $19 \%$ & & \\
\hline \multirow[t]{3}{*}{ iacm } & 1, Medium & $42 \%$ & - & - \\
\hline & 2, High & $39 \%$ & & \\
\hline & 0, Low (Base) & $22 \%$ & & \\
\hline orgm & $\begin{array}{l}\text { 1, Medium } \\
\text { 2, High }\end{array}$ & $\begin{array}{c}72 \% \\
5 \%\end{array}$ & - & - \\
\hline transptotal_rate & Percentage & $53 \%$ & $55.2 \%$ & $25.8 \%$ \\
\hline subdeinvesttrans & $\begin{array}{c}\times 1000 \text { annual CLP per } \\
\text { inhabitant }\end{array}$ & 50.52 & 11.88 & 232.00 \\
\hline
\end{tabular}

Note: partFCM, proportion of municipal budget from the Municipal Common Fund; pmarate, percentage of municipal staff working on environmental issues; perate, percentage of municipal staff working on civil protection; prof_muni_rate, percentage of municipal staff holding a bachelor's degree; edumayor, mayor's education level; mayorvote_rate, percentage of mayor's winning votes in election; council_coalition, percentage of councilors in same political coalition as mayor; iacm, municipal council's accountability index; orgm, municipal organization index; transptotal_rate, percentage of compliance with transparency standards; subdemanagtrans, amount of annual monetary transfers per capita to improve management; subdeinvesttrans, amount of annual monetary transfers per capita to improve urban equipment; gastranscor, amount of annual monetary transfers per capita from regional government; horizontal_network, amount of annual monetary transfers per capita between municipalities; CLP, Chilean pesos.

\section{Appendix C}

Simplified version of the model, xttobit command syntaxis.

$y_{i t}=\beta_{0}+\beta_{1} x_{1 i t}+\beta_{2} x_{2 i t}+\beta_{3} x_{1 i t} x_{2 i t}+$ Controls $+\varepsilon_{i t}$, where controls include all relevant variables and dummy variables such that $E\left(\varepsilon_{i t} \mid x_{i t}, z_{i t}\right.$, controls $)=0 . \varepsilon_{i t}$ is a unit-specific random effects component.

1. Parameters $\left(\beta_{0}, \beta_{1}, \beta_{2}, \beta_{3}\right)$ estimation: xttobit $y$ controls $x_{1} \# \#\left(x_{2}\right), 11(0)$ tobit

2. Marginal effects-post estimation commands:

2.1. Direct effect: $\operatorname{dydx}\left({ }^{*}\right)$ predict $(y \operatorname{star}(0,)$.

2.2. Moderating effect of $x_{2}$ on the effect of $x_{1}$ on $y$

2.2.1. Case $1, x_{1}$ and $x_{2}$ are continuous:

margins, expression $\left(\operatorname{normal}\left(\mathrm{xb}() /\left(\operatorname{sqrt}\left(\mathrm{e}\left(\operatorname{sigma} \_\mathrm{u}\right)^{\wedge} 2+\mathrm{e}(\text { sigma_e })^{\wedge} 2\right)\right)\right) *\left(\_\mathrm{b}\left[x_{1}\right]+x_{2} * \_\mathrm{b}\left[x_{1} \# x_{2}\right]\right)\right) \mathrm{dydx}\left(x_{2}\right)$ 
2.2.2. Case $2, x_{1}$ is categorical and $x_{2}$ is continuous:

$$
\text { margins } x_{1}, \operatorname{dydx}\left(\text { c. } x_{2}\right) \text { pwcompare }
$$

2.2.3. Case $2, x_{1}$ and $x_{2}$ are categorical:

$$
\text { margins } x_{1}, \operatorname{dydx}\left(i, x_{2}\right) \text { pwcompare }
$$

\section{Appendix D}

Case selection, data collection, and data analysis, complementary information

Chile is a unitary and centralized republic with a presidential system (Figure A1). Until 2016, the country was territorially divided into 15 regions, 54 provinces, and 346 communities (entities with cities, towns, villages, and rural areas) (Figures A2 and A3). Each regional government was headed by an intendant, appointed by the President of the Republic, and a regionally elected council represented the communities. The national ministries had regional secretariats subordinated to the intendent's authority. The administration of each province was headed by a governor appointed by the President of the Republic, exercising powers in accordance with the instructions from the regional intendant. The local government of each community consisted of a mayor and a municipal council elected

\begin{tabular}{|c|c|}
\hline \multirow[t]{3}{*}{ Chile } & Unitary and centralized republic \\
\hline & Presidential system \\
\hline & Ministries, regional, and provintial authorities designed by the Presidency \\
\hline \multirow[t]{4}{*}{ Deconcentration } & Ministerial regional secretariats (24) \\
\hline & Regional intendants (16) \\
\hline & Regionally elected councils (16) \\
\hline & Province governors (54) \\
\hline \multirow[t]{3}{*}{ Decentralization } & Municipalities (346) \\
\hline & Entities with cities, towns, villages, and rural areas \\
\hline & Local governments: mayor and municipal council, elected \\
\hline
\end{tabular}
directly by the residents for a period of four years, which could be renewed.

Figure A1. Administrative-political structure in Chile, 2009-2016 [46,49].

\section{Appendix D.1 Case Selection}

We selected municipalities located in south-central Chile, where $90 \%$ of the country's population lives and which had populations at risk regarding geographical and environmental conditions, socioeconomic fragilities, and need for more infrastructure (Figure A3). 


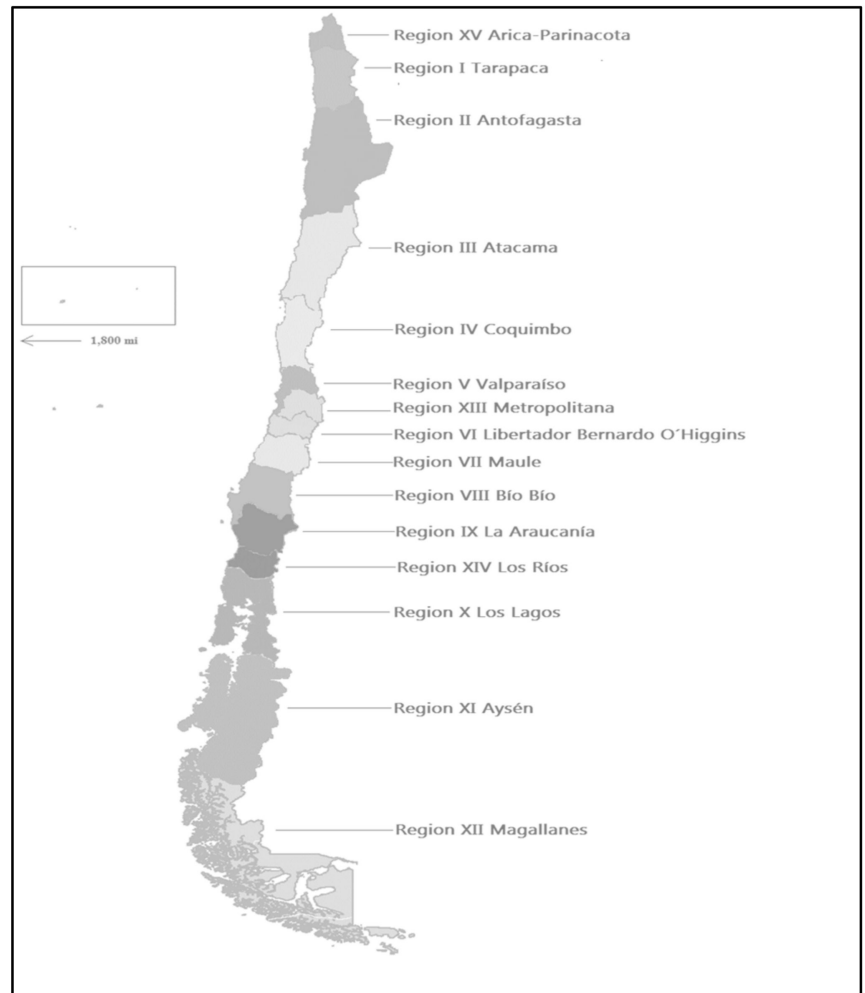

Figure A2. Chilean regions, 2009-2016 [46].

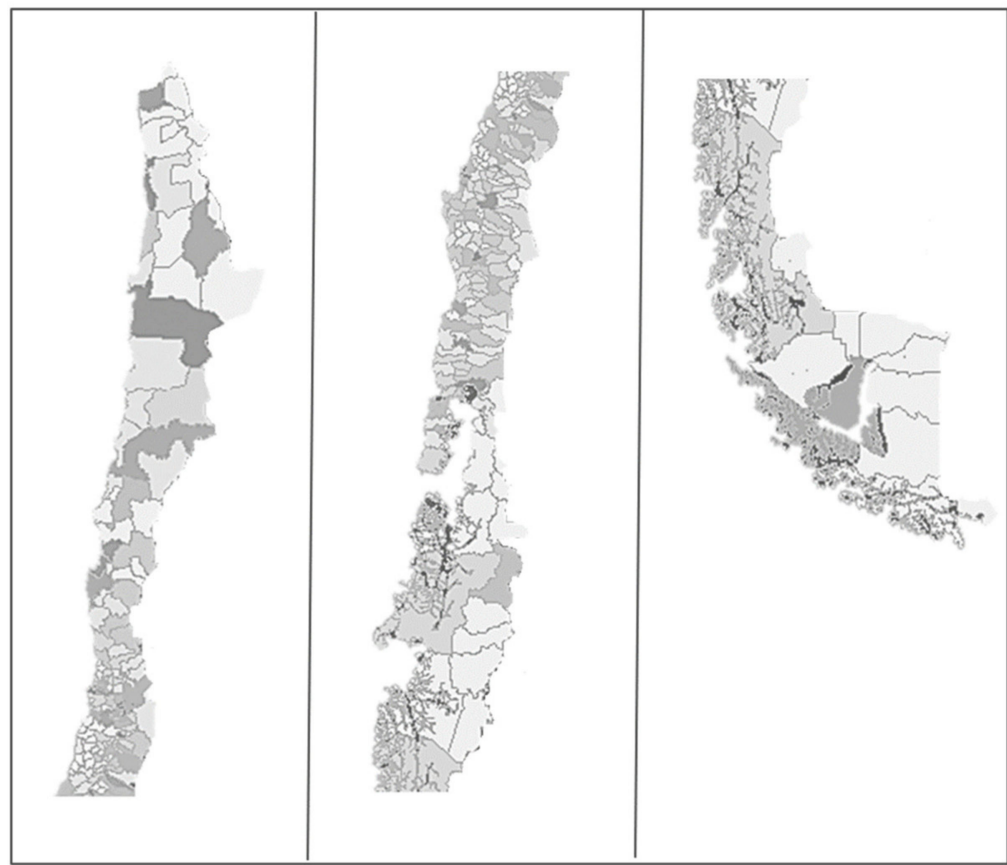

Figure A3. Chilean municipalities, 2009-2016 [45]. Most of Chile's population live in municipalities located in the center south of the country. 


\begin{tabular}{|c|c|}
\hline \multirow[t]{3}{*}{ Location } & Coastline \\
\hline & Valley \\
\hline & Mountain range \\
\hline \multirow[t]{2}{*}{ Population } & 44 cases with population greater than 70,000 \\
\hline & 58 cases with population between 3000 and 70,000 \\
\hline \multirow[t]{5}{*}{ Risk } & Environmental conditions \\
\hline & Climate change \\
\hline & Socioeconomic fragilities \\
\hline & High risk perception \\
\hline & Lack of critical infrastructure \\
\hline \multirow[t]{5}{*}{ Disasters } & Hydrometeorological \\
\hline & Geophysical \\
\hline & Biological \\
\hline & Environmental \\
\hline & Technological \\
\hline
\end{tabular}

Figure A4. Selection criteria.

\section{Appendix D.2 Data Collection}

We systematically worked on the information during 2016-2021, obtained missing documentation by requesting complementary information from municipalities, ministries, and public services, and triangulated different sources of information on the same matters of interest (Figures 2 and 5 and Figure A12). For example, we collected information on investments through semi-structured interviews in the case-study municipalities, and from official data and consultations by correspondence, telephone, and active transparency. In order to complete the list of transfer agreements in the illustrative nine cases during 2009-2016, we first reviewed the list of agreements for each year available in the active transparency sections of the municipal websites, the municipal decrees of the same period, and registry of collaborators in the Ministry of Economy, complementing it with a detailed reading of the annual public accounts of the mayors, and validating the information produced with municipal officials (interviews, focus groups, and passive transparency).

In our study, we used semi-structured interviews applied face-to-face to a sample of functionaries of 98 municipalities. The interviews were designed to be applied to municipal officials with managerial positions, conducted by the contracted professional Group Demoscopica and researchers of the National Fund for Scientific and Technological Research, FONDECYT between April 2015 and December 2016 (Figure 4). All the directors of civil protection and emergencies agreed to participate in the study, while participation of the other officials was around 30\%. For this reason, we included in the qualitative analysis only the responses of directors of civil protection and emergencies for comparison. 


\begin{tabular}{cc}
\hline Protocols, design & Guidelines \\
\cline { 2 - 3 } & Questionnaire \\
\hline Contact strtategy & Onformed consent \\
\cline { 2 - 3 } & Mail \\
\hline Training & Telephone \\
\cline { 2 - 3 } & Face-to-Face \\
\hline Application & Protocols \\
\hline & Researchers \\
\hline Control and validation & Students \\
\cline { 2 - 4 } & Demoscopica Group \\
\hline & Municipalities \\
\hline & Recorded interviews \\
\hline & Demoscopica Group \\
\hline & Principal Researcher \\
\hline & Assistant researchers \\
\hline
\end{tabular}

Figure A5. Semi-structured interviews in municipalities, steps [56].

\begin{tabular}{ccc}
\hline Demoscopica GROUP & 79 municipalities, nine regions \\
\cline { 2 - 3 } & & 159 senior officials \\
\cline { 2 - 3 } $\begin{array}{c}\text { Researchers National } \\
\text { Fund for Scientific and } \\
\text { Technological Research, }\end{array}$ & April 2015 and March 2016 \\
\cline { 2 - 2 } & 19 municipalities, six regions \\
\cline { 2 - 2 } & 45 senior officials \\
\hline
\end{tabular}

Figure A6. Semi-structured interviews in municipalities, sample [56].

Mayor office

Planning office

Public works office

Social well-being office

Civil protection and emergencies office

Figure A7. Five types of municipal officials with managerial positions [56]. 




Figure A8. Semi-structured interviews in municipalities, protocol [56].

The protocol of the semi-structured interview contained 33 open and pre-coded questions (Figure A9).

Risk perception

Experiences (extreme weather events, disasters)

Programs and actions for DRR

Municipal organization

Coordination and interactions (experience, frequency)

Integration

Municipal council

Planning (e.g., date, reasons, update, personnel,, funds)

Governance

Performance (agreements, evaluations)

Data, sources of information

Demographic data

Figure A9. Open and pre-coded questions (total of 33) [56].

We employed several programs to populate databases and produce inputs for the analysis (Figures A10 and A11). 


\begin{tabular}{|c|c|}
\hline \multirow[t]{4}{*}{ Statistics } & Excel, Microsoft 365 \\
\hline & Mathematica, Wolfgram 11.3 \\
\hline & SPSS Statistics 23 \\
\hline & Statistics/Data Analysis (STATA), 14.0 and 16.0 \\
\hline \multirow[t]{3}{*}{ Content analysis } & NVivo 2018 \\
\hline & ATLAS.ti 8 Windows \\
\hline & Figure A10. Programs employed in data analysis. \\
\hline \multicolumn{2}{|r|}{ Statistics } \\
\hline \multirow{7}{*}{\multicolumn{2}{|c|}{$\begin{array}{c}\bullet \text { Programming } \\
\bullet \text { Testing data consistency } \\
\bullet \text { Coding/recoding } \\
\bullet \text { Frequencies and percentages } \\
\bullet \text { Central tendency analysis } \\
\bullet \text { Association test } \\
\bullet \text { Regressions }\end{array}$}} \\
\hline & \\
\hline & \\
\hline & \\
\hline & \\
\hline & \\
\hline & \\
\hline \multicolumn{2}{|r|}{ Content analysis } \\
\hline \multicolumn{2}{|r|}{-Descriptive coding } \\
\hline \multicolumn{2}{|r|}{ •Recurrence coding } \\
\hline \\
\hline \multicolumn{2}{|r|}{-Sequence of thematic analysis } \\
\hline \multicolumn{2}{|r|}{-Metainterpretations } \\
\hline \multicolumn{2}{|r|}{ Validation of results } \\
\hline \multicolumn{2}{|r|}{ •Workshops } \\
\hline \multicolumn{2}{|r|}{ - Thesis projects } \\
\hline
\end{tabular}

Figure A11. Procedures employed in data analysis.

The research team (senior researchers, undergraduate and graduate students, and professional collaborators) searched document sources and conducted semi-structured interviews with qualified informants in the nine selected cases (Figure 4). Through FONDECYT (National Fund for Scientific and Technological Research) projects, we conducted semi-structured interviews with municipal officials (directors for environment, emergencies, planning, public works, social well-being), with questions on DRR, adaptation planning, critical infrastructure investments, capacities, leadership, organization, multilevel governance, and perceptions (e.g., climate-change, risks, coordination). The application of interviews included: (1) preparation of protocols and strategy for making contact, to inform potential participants about our research, and arrange meetings; (2) training of the research team, undergraduate students, and thesis students to conduct interviews; (3) applying and recording interviews with open questions related to the research topics; and (4) analysis of results by focus groups, workshops, and thesis direction. We also reviewed available municipal official records for 2009-2016, such as municipal annual public accounts, communality development plans, municipal internal regulations, budgetary data, and meeting minutes of municipal councils (Figure 5).

We systematically worked on the information during 2016-2021, obtained missing documentation by requesting complementary information from municipalities, ministries, 
and public services, and triangulated different sources of information on the same matters of interest (Figure A12). For example, we collected information on investments through semi-structured interviews in the case-study municipalities, and from official data and consultations by correspondence, telephone, and active transparency. In order to complete the list of transfer agreements in the illustrative nine cases during 2009-2016, we first reviewed the list of agreements for each year available in the active transparency sections of the municipal websites, the municipal decrees of the same period, and registry of collaborators in the Ministry of Economy, complementing it with a detailed reading of the annual public accounts of the mayors, and validating the information produced with municipal officials (interviews, focus groups, and passive transparency).

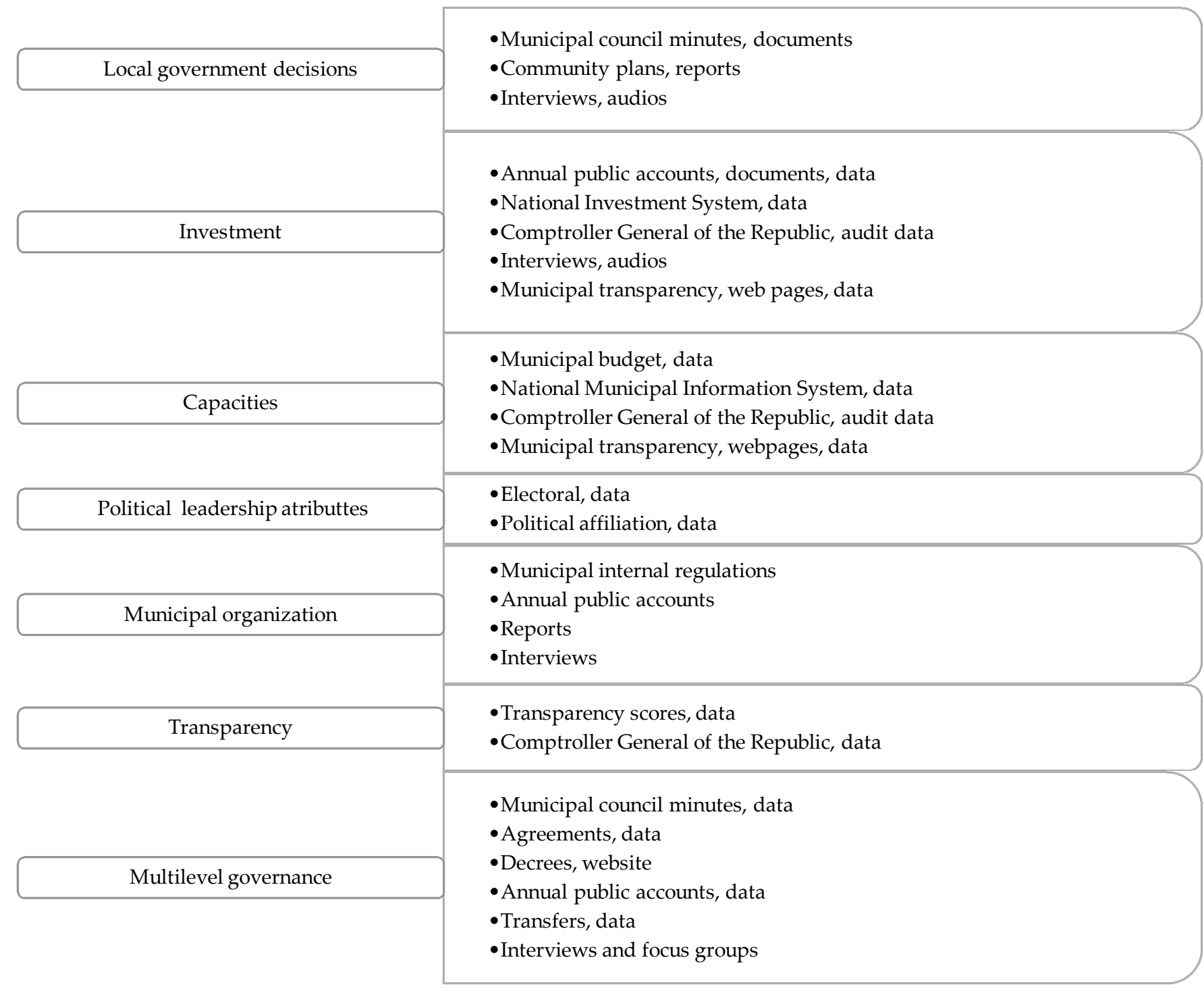

Figure A12. Concepts (latent) and triangulation of data (manifest variables). 


\section{Appendix E}

Table A3. Effects of capacities, leadership, and accountability as moderator.

\begin{tabular}{|c|c|c|}
\hline Variables & Model 1: Investment & Model 2: Maintenance \\
\hline partFCM_rate & $0.84614^{* * *}$ & -118.346 \\
\hline medium (base: low) $\times$ partFCM_rate & -1.206 .112 & $-5.64391 * *$ \\
\hline high (base: bajo) $\times$ partFCM_rate & 0.3806593 & -191.648 \\
\hline Pmarate & 0.32313 & 199.059 \\
\hline medium (base: low) $\times$ pmarate & 1.270 .784 & -435.189 \\
\hline high $($ base: low $) \times$ pmarate & 1.643 .535 & -344.245 \\
\hline Perate & 0.56664 & 341.424 \\
\hline medium (base: low) $\times$ perate & -1.574 .757 & -1.564 .425 \\
\hline high $($ base: low $) \times$ perate & -4.497 .749 & -2.281 .455 \\
\hline prof_muni_rate & -0.61795 & $4.77559 * * *$ \\
\hline medium (base: low) $\times$ prof_muni_rate & 0.5767846 & $13.78759 * * *$ \\
\hline high $($ base: low $) \times$ prof_muni_rate & 1.623 .527 & 0.25064 \\
\hline edumayor (technical) & -307.692 & 2.317 .893 \\
\hline medium (base: low) $\times$ edumayor & -8.723 .003 & -15.953 .990 \\
\hline high $($ base: low) $\times$ edumayor & 5.397 .387 & -2.402 .755 \\
\hline edumayor (professional) & 323.677 & 358.932 \\
\hline medium (base: low) $\times$ edumayor & -5.878 .114 & -4.888 .378 \\
\hline high (base: low) $\times$ edumayor & 3.552 .982 & -1.279 .376 \\
\hline mayorvote_rate & 0.34824 & 291.780 \\
\hline medium (base: low) $\times$ mayorvote_rate & $4.85202 * * *$ & $-14.26488^{* * *}$ \\
\hline high $($ base: low $) \times$ mayorvote_rate & 3.508 .063 & $-12.90603^{* *}$ \\
\hline council_coalition & $-0.404916^{* *}$ & $-1.684582 * *$ \\
\hline medium (base: low) $\times$ council_coalition & -0.491772 & 1.998 .828 \\
\hline high $($ base: low $) \times$ council_coalition & -0.71 .5589 & 1.797 .725 \\
\hline Rulingparty & $18.42414^{* *}$ & -1.286 .452 \\
\hline medium (base: low) $\times$ rulingparty & -2.691 .243 & 388.681 \\
\hline high $($ base: low) $\times$ rulingparty & 1.343 .677 & 6.652 .708 \\
\hline Incumbent & 14.46393 * & 1.614 .288 \\
\hline medium (base: low) $\times$ incumbent & 4.585 .507 & 10.859 .117 \\
\hline high $($ base: low $) \times$ incumbent & 2.184 .817 & 5.999 .462 \\
\hline iacm (Medium, base: Low) & 1.148 .032 & -5.195 .023 \\
\hline iacm (High, base: Low) & 748.007 & -8.665 .127 \\
\hline orgm (Medium, base: Low) & 340.030 & 9.709 .894 \\
\hline orgm (High, base: Low) & 4.274 .493 & 8.664 .163 \\
\hline transptotal_rate & -0.22212 & -0.12968 \\
\hline Coastline & 1.035 .576 & 2.921 .506 \\
\hline valley-mountain & 239.633 & -0.63852 \\
\hline Size & $0.00450 * *$ & $-0.05334^{* * *}$ \\
\hline Rainfall & 0.91262 & 0.06068 \\
\hline Temperature & -0.01673 & 0.36430 \\
\hline pover_rate & -0.07061 & -0.52588 \\
\hline unemploy_rate & 263.907 & -1.104 .613 \\
\hline ethnic_rate & $1.43475^{* * *}$ & $4.88791^{* *}$ \\
\hline cap_region & 1.405 .354 & 0.00038 \\
\hline Density & -0.00118 & 0.000001 \\
\hline urb_rate & -0.47204 * & $-2.91397^{* * *}$ \\
\hline num_eve_clim_hig & 1.078 .131 & $55.23354^{* *}$ \\
\hline num_eve_clim & -0.14427 & $-3.68663 * *$ \\
\hline earqk10_deaths & -0.21178 & -142.251 \\
\hline earqk10_scale & 816.027 & -1.636 .648 \\
\hline reported0814 & -136.793 & -431.245 \\
\hline no_illegal_settlements & 1.842 .745 & -1.514 .096 \\
\hline num_plantacontrata & -0.02152 & 0.11696 \\
\hline
\end{tabular}


Table A3. Cont.

\begin{tabular}{lcc}
\hline Variables & Model 1: Investment & Model 2: Maintenance \\
\hline regional fixed effects & YES & YES \\
time fixed effects & YES & YES \\
RE (county) & YES & YES \\
adjusted Rho-squared & 0.1996 & 0.2262 \\
No of observations & 1626 & 1454 \\
\hline
\end{tabular}

${ }^{*} 10 \%,{ }^{* *} 5 \%,{ }^{* * *} 1 \%$ significance level.

Table A4. Effects of capacities, leadership, and resource transfers as moderators.

\begin{tabular}{|c|c|c|}
\hline Variables & Model 3: Investment & Model 4: Maintenance \\
\hline partFCM_rate & $0.95611^{* * *}$ & $-2.03521 *$ \\
\hline interaction $\times$ partFCM_rate & 0.00469 & $-0.14008^{* * *}$ \\
\hline Pmarate & -220.363 & -1.157 .431 \\
\hline interaction $\times$ pmarate & -0.07790 & $-0.49204 *$ \\
\hline Perate $\mathrm{P}$ - & -0.21570 & 816.279 \\
\hline interaction $\times$ perate & 2.080 .444 & $0.35228^{* *}$ \\
\hline prof_muni_rate & -0.61014 & $4.38795 * *$ \\
\hline interaction $\times$ prof_muni_rate & -0.00315 & $0.12606^{* * *}$ \\
\hline edumayor (technical) & 234.609 & -1.615 .647 \\
\hline interaction $\times$ edumayor & -0.842372 & -0.20869 \\
\hline edumayor (professional) & $-0.842372^{* * *}$ & -2.322 .270 \\
\hline interaction $\times$ edumayor & $-1.214724 * * *$ & -0.15584 \\
\hline mayorvote_rate & 0.30316 & 4.21960 ** \\
\hline interaction $\times$ mayorvote rate & $-0.01622 *$ & 0.02872 \\
\hline council_coalition & $-0.529106^{* * *}$ & $-1.577342 * *$ \\
\hline interaction $\times$ council_coalition & $-0.010583^{* * *}$ & $-0.357629^{* *}$ \\
\hline Rulingparty & 16.70460 ** & -2.807 .512 \\
\hline interaction $\times$ rulingparty & -0.2678327 & $-1.91807^{* * *}$ \\
\hline Incumbent & $22.44683^{* * *}$ & 2.661 .684 \\
\hline interaction $\times$ incumbent & $1.113316^{* * *}$ & $3.38906^{* * *}$ \\
\hline Subdemanagtranshab & $1.15707 *$ & -0.59521 \\
\hline Subdeinvesttranshab & -0.44622 & 212.849 \\
\hline gastranscor reghab & -0.00109 & -0.09284 \\
\hline horizontal_networkhab & 0.00005 & 0.00006 \\
\hline Coastline & 645.979 & 1.998 .859 \\
\hline valley-mountain & 416.873 & 2.590 .524 \\
\hline Size & $0.00574 * * *$ & $-0.05255^{* * *}$ \\
\hline Rainfall & -0.01310 & 0.04569 \\
\hline Temperature & 0.86191 & -0.22025 \\
\hline pover_rate & -0.11429 & 0.07495 \\
\hline unemploy_rate & $3.58730 *$ & -554.504 \\
\hline ethnic_rate & $1.53013^{* * *}$ & $3.98765^{* *}$ \\
\hline cap_region & 624.880 & 5.184 .679 \\
\hline Density & -0.00218 & 0.00232 \\
\hline urb_rate & -0.34390 & $-2.50651 * *$ \\
\hline num_eve_clim_hig & $12.29390 * *$ & $53.92427 * *$ \\
\hline num_eve_clim & -0.23489 & $-2.67605^{*}$ \\
\hline earqk10_deaths & -0.01089 & -0.87266 \\
\hline earqk10_scale & 811.540 & -442.482 \\
\hline reported 0814 & 0.36276 & -495.383 \\
\hline no_illegal_settlements & 1.491 .111 & -780.230 \\
\hline num_plantacontrata & -0.22450 & 0.35171 \\
\hline regional fixed effects & YES & YES \\
\hline time fixed effects & YES & YES \\
\hline RE (comuna) & YES & YES \\
\hline adjusted Rho-squared & 0.2349 & 0.2543 \\
\hline No of observations & 1.626 & 1454 \\
\hline
\end{tabular}

${ }^{*} 10 \%,{ }^{* *} 5 \%,{ }^{* * *} 1 \%$ significance level. 
Table A5. Effects of capacities, leadership, and municipal organization as moderators.

\begin{tabular}{|c|c|c|}
\hline Variables & Model 5: Investment & Model 6: Maintenance \\
\hline partFCM_rate & $0.82661 * * *$ & -113.760 \\
\hline medium (base: low) $\times$ partFCM_rate & -0.6967037 & -329.817 \\
\hline high (base: bajo) $\times$ partFCM_rate & $8.48499 * * *$ & -304.874 \\
\hline Pmarate & 204.944 & 548.559 \\
\hline medium (base: low) $\times$ pmarate & 3.332 .897 & -324.323 \\
\hline high $($ base: low $) \times$ pmarate & 6.094 .854 & 9.077 .675 \\
\hline Perate & 0.81822 & 368.485 \\
\hline medium (base: low) $\times$ perate & -7.453 .823 & -1.558 .892 \\
\hline high (base: low) $x$ perate & -1.712 .324 & -1.353 .712 \\
\hline prof_muni_rate & -0.55399 & $5.51509^{* * *}$ \\
\hline medium (base: low) $\times$ prof_muni_rate & 1.167 .583 & $9.28556 * *$ \\
\hline high $($ base: low $) \times$ prof_muni_rate & -4.114 .763 & -252.113 \\
\hline edumayor (technical) & 180.420 & 1.881 .865 \\
\hline medium (base: low) $\times$ edumayor & -2.750 .327 & -6.866 .637 \\
\hline high (base: low) $\times$ edumayor & 1.380 .645 & -2.413 .567 \\
\hline edumayor (professional) & 563.107 & -482.699 \\
\hline medium (base: low) $\times$ edumayor & -3.258 .027 & -4.949 .822 \\
\hline high (base: low) $\times$ edumayor & 128.997 & -17.148 .606 \\
\hline mayorvote_rate & $1.09634^{* *}$ & 306.746 \\
\hline medium (base: low) $\times$ mayorvote_rate & 1.710 .782 & $-10.71454^{* *}$ \\
\hline high $($ base: low $) \times$ mayorvote_rate & $38.26841 * * *$ & -1.101 .569 \\
\hline council_coalition & -0.270838 & $-1.428652 *$ \\
\hline medium (base: low) $\times$ council_coalition & -0.818493 & 2.230 .169 \\
\hline high $($ base: low) $\times$ council_coalition & 2.661 .787 & 1.899 .637 \\
\hline Rulingparty & $19.94061 * * *$ & -1.530 .918 \\
\hline medium (base: low) $\times$ rulingparty & 9.328 .835 & 967.592 \\
\hline high $($ base: low) $\times$ rulingparty & 7.984 .552 & 371.413 \\
\hline Incumbent & $16.36236^{* *}$ & 720.539 \\
\hline medium (base: low) $\times$ incumbent & 5.697 .539 & 4.573 .341 \\
\hline high (base: low) $\times$ incumbent & -9.170 .789 & 1.853 .434 \\
\hline iacm (medium, base: Low) & -1.001 .691 & -7.391 .593 \\
\hline iacm (high, base: Low) & -1.803 .071 & -12.163 .967 \\
\hline orgm (medium, base: Low) & 2.447 .997 & 12.542 .401 \\
\hline orgm (high, base: Low) & $150.37013^{* * *}$ & 13.761 .530 \\
\hline transptotal_rate & -0.15831 & -0.07838 \\
\hline Coastline & 1.331 .887 & 519.391 \\
\hline valley-mountain & 717.044 & 339.381 \\
\hline Size & $0.00505^{* * *}$ & $-0.05719^{* * *}$ \\
\hline Rainfall & -0.01630 & 0.05507 \\
\hline Temperature & 114.045 & 166.029 \\
\hline pover_rate & 0.32793 & -0.58197 \\
\hline unemploy_rate & 229.028 & -879.040 \\
\hline ethnic_rate & $1.26995^{* * *}$ & $4.93559 * *$ \\
\hline cap_region & 760.688 & 4.652 .036 \\
\hline Density & -0.00131 & 0.00653 \\
\hline urb_rate & -0.39979 & $-2.82187^{* *}$ \\
\hline num_eve_clim_hig & 13.23202 * & $62.62578 * *$ \\
\hline num_eve_clim & -0.30934 & $-2.78529 *$ \\
\hline earqk10_deaths & -0.23281 & -159.552 \\
\hline earqk10_scale & 647.751 & -768.231 \\
\hline reported 0814 & -244.646 & -678.367 \\
\hline no_illegal_settlements & 932.760 & -2.232 .422 \\
\hline num_plantacontrata & -0.02611 & -0.08732 \\
\hline regional fixed effects & YES & YES \\
\hline time fixed effects & YES & YES \\
\hline RE (comuna) & YES & YES \\
\hline adjusted Rho-squared & 0.2205 & 0.2174 \\
\hline No of observations & 1626 & 1454 \\
\hline
\end{tabular}

${ }^{*} 10 \%,{ }^{* *} 5 \%,{ }^{* * *} 1 \%$ significance level. 


\section{References}

1. Betsill, M. Mitigating climate change in US cities. Local Environ. 2001, 6, 393-406. [CrossRef]

2. Carmin, J.; Anguelovski, I.; Roberts, D. Urban climate adaptation in the Global South. J. Plan. Educ. Res. 2012, 32, 18-32. [CrossRef]

3. Valdivieso, P.; Andersson, K.P.; Villena-Roldán, B. Institutional drivers of adaptation in local government decision-making. Clim. Chang. 2017, 143, 151-171. Available online: https:/ / static--content.springer.com/esm/art\%3A10.1007\%2Fs10584--017--1961--9 /MediaObjects/10584_2017_1961_MOESM1_ESM.pdf (accessed on 20 December 2018). [CrossRef]

4. Valdivieso, P.; Andersson, K.P. What Motivates Local Governments to Invest in Critical Infrastructure? Lessons from Chile. Sustainability 2018, 10, 3808. [CrossRef]

5. Bernauer, T. Climate Change Politics. Annu. Rev. Polit. Sci. 2013, 16, 421-448. [CrossRef]

6. Organisation for Economic Co-Operation and Development. Good Governance for Critical Infrastructure Resilience; OECD: Paris, France, 2019.

7. Carleton, T.A.; Hsiang, S.M. Social and economic impacts of climate. Science 2016, 353, aad9837. [CrossRef] [PubMed]

8. Intergovernmental Panel on Climate Change. Managing the Risks of Extreme Events and Disasters to Advance Climate Change Adaptation; Special Report; Cambridge University Press: Cambridge, UK, 2012.

9. McGee, S.; Frittman, J.; Seongjin, J.A.; Murray, S. Risk Relationships and Cascading Effects in Critical Infrastructures: Implications for the Hyogo Framework; United Nations International Strategy for Disaster Reduction: Geneva, Switzerland, 2014.

10. Forzieri, G.; Bianchi, A.; Batista, F.; Marin, M.; Leblois, A.; Lavalle, C.; Aerts, J.; Feyen, L. Escalating impacts of climate extremes on critical infrastructures in Europe. Glob. Environ. Chang. 2018, 48, 97-107. [CrossRef] [PubMed]

11. Huskova, I.; Matrosov, E.; Harou, J.; Kasprzyk, J.; Lambert, C. Screening robust water infrastructure investments and their trade-offs under global change: A London example. Glob. Environ. Chang. 2016, 41, 216-227. [CrossRef]

12. Organisation for Economic Co-Operation and Development. Climate-Resilient Infrastructure; OECD: Paris, France, 2018.

13. Revi, A.; Satterthwaite, D.E.; Aragón-Durand, F.; Corfee-Morlot, J.; Kiunsi, R.B.R.; Pelling, M.; Roberts, D.C.; Solecki, W. Urban areas. In Climate Change; Field, C.B., Barros, V.R., Dokken, D.J., Mach, K.J., Mastrandrea, M.D., Bilir, T.E., Chatterjee, M., Ebi, K.L., Estrada, Y.O., Genova, R.C., et al., Eds.; Cambridge University Press: Cambridge, UK, 2014; pp. 538-541, 546, 552, 563-575, 577.

14. Fay, M.; Atsushi, I.; Perrissin-Fabert, B. Financing Greener and Climate-Resilient Infrastructure in Developing Countries; Atsushi, I., Perrissin-Fabert, B., Eds.; European Investment Bank (EIB): Luxembourg, 2010.

15. Inter-American Development Bank. Policy Evaluation Framework on the Governance of Critical Infrastructure Resilience in Latin America; Inter-American Development Bank: Washington, DC, USA, 2017.

16. Valdivieso, P. Institutional analysis on the governance of disaster risk reduction at the local level. Analysis with Chilean municipalities. In Multiscale, Regional, and Local Planning; Cuervo, L., Délano, M., Eds.; United Nations Economic Commission for Latin America and the Caribbean (CEPAL): Santiago, Chile, 2019; pp. 233-255. Available online: https://repositorio.cepal.org/ handle/11362/44845 (accessed on 11 July 2021). (In Spanish)

17. Ostrom, E. Understanding Institutional Diversity; Princeton University Press: Princeton, NJ, USA, 2005.

18. Funder, M.; Mweemba, C.M. Interface bureaucrats and the everyday remaking of climate interventions: Evidence from climate change adaptation in Zambia. Glob. Environ. Chang. 2019, 55, 130-138. [CrossRef]

19. Hardin, R. Collective Action as an Agreeable n-Prisoners' Dilemma. Science 1971, 16, 472-481. [CrossRef]

20. Haynes, K.; Yoder, K. Offsetting Uncertainty: Reassurance with Two-Sided Incomplete Information. Am. J. Political Sci. 2020, 64, 38-51. [CrossRef]

21. Coleman, E.; Mwangi, E. Conflict, Cooperation, and Institutional Change on the Commons. Am. J. Political Sci. 2015, 59, 855-865. [CrossRef]

22. Downs, A. Inside Bureaucracy; Little Brown: Boston, MA, USA, 1967; pp. 2, 25.

23. Duvat, V.K.E.; Volto, N.; Stahl, L.; Moatty, A.; Defossez, S.; Desarthe, J.; Grancher, D.; Pillet, V. Understanding interlinkages between long-term trajectory of exposure and vulnerability, path dependency and cascading impacts of disasters in Saint-Martin (Caribbean). Glob. Environ. Chang. 2021, 67. [CrossRef]

24. Bhavnani, R.; Lee, A. Does Affirmative Action Worsen Bureaucratic Performance? Evidence from the Indian Administrative Service. Am. J. Political Sci. 2021, 65, 5-20. [CrossRef]

25. Velasco, C. Loyalty or Incentives? How Party Alignment Affects Bureaucratic Performance. J. Politics 2020, 82, 1287-1304.

26. Stark, A.; Head, B. Institutional amnesia and public policy. J. Eur. Public Policy 2019, 26, 1521-1539. [CrossRef]

27. Ostrom, E. Governing the Commons: The Evolution of Institutions for Collective Action; Cambridge University Press: New York, NY, USA, 1990.

28. Ostrom, E. Collective Action and the Evolution of Social Norms. J. Econ. Perspect. 2000, 14, 137-158. [CrossRef]

29. Hayhoe, K.; Robson, M.; Rogula, J.; Auffhammer, M.; Miller, N.; Van Dorn, J.; Wuebbles, D. An integrat-ed framework for quantifying and valuing climate change impacts on urban energy and infrastructure: A Chicago case study. J. Great Lakes Res. 2010, 36, 94-105. [CrossRef]

30. Schmidt, N.; Meyer, M.D. Incorporating Climate Change Considerations into Transportation Planning. Transp. Res. Rec. 2009, 2119, 66-73. [CrossRef]

31. Innes, J.E.; Booher, D.E. Consensus building and complex adaptive systems: A framework for evaluating collaborative planning. J. Am. Plan. Assoc. 1999, 65, 412-423. [CrossRef]

32. Berke, P.R.; Campanella, T.J. Planning for postdisaster resiliency. Ann. Am. Acad. Political Soc. Sci. 2006, 604, 192-207. [CrossRef] 
33. Simpson, D.M.; Rockaway, T.D.; Weigel, T.A.; Coomes, P.A.; Holloman, C.O. Framing a new approach to critical infrastructure modelling and extreme events. Int. J. Crit. Infrastruct. 2005, 1, 125-143. [CrossRef]

34. Aylett, A. Institutionalizing the urban governance of climate change adaptation: Results of an international survey. Urban Clim. 2015, 14, 4-16. [CrossRef]

35. Lesnikowski, A.; Biesbroek, R.; Ford, J.D.; Berrang-Ford. Policy implementation styles and local governments: The case of climate change adaptation. Environ. Politics 2020. [CrossRef]

36. Cashmore, M.; Wejs, A. Constructing legitimacy for climate change planning: A study of local government in Denmark. Glob. Environ. Chang. 2014, 24, 203-212. [CrossRef]

37. Kousser, T.; Tranter, B. The influence of political leaders on climate change attitudes. Glob. Environ. Chang. 2018, 50, 100-109. [CrossRef]

38. Williams, D.S.; Celliers, L.; Unverzagt, K.; Videira, N.; Máñez Costa, M.; Giordano, R.A. A method for enhancing capacity of local governance for climate change adaptation. Earth's Future 2020, 8, e2020EF001506. [CrossRef]

39. Friedrich, R. In Defense of Multiplicative Terms in Multiple Regression Equations. Am. J. Political Sci. 1982, 26, 797-833. [CrossRef]

40. Wooldridge, J.M. Control function methods in applied econometrics. J. Hum. Resour. 2015, 50, 420-445. [CrossRef]

41. Nitzl, C.; Hilgers, D.; Hirsch, B.; Lindermüller, D. The Influence of the Organizational Structure, Environment, and Resource Provision on the Use of Accrual Accounting in Municipalities. Schmalenbach Bus Rev. 2020, 72, 271-298. [CrossRef]

42. Bulkeley, H.; Betsill, M. Revisiting the urban politics of climate change. Environ. Polit 2013, 22, 136-154. [CrossRef]

43. Bulkeley, H.; Betsill, M. Cities and Climate Change: Urban Sustainability and Global Environmental Governance; Routledge: Oxon, NY, USA, 2003.

44. Park, A.; Krause, R.; Hawkins, C. Institutional Mechanisms for Local Sustainability Collaboration: Assessing the Duality of Formal and Informal Mechanisms in Promoting Collaborative Processes. J. Public Adm. Res. Theory 2021, 31, 434-450. [CrossRef]

45. IDEchile. Geospatial Data Infrastructure; Ministerio de Bienes Nacionales: Santiago, Chile, 2021; Available online: https://www. ide.cl/index.php (accessed on 21 June 2018). (In Spanish)

46. Geographic Military Institute. Maps of Chile; Instituto Geográfico Militar: Santiago, Chile, 2021; Available online: https: / / www.igm.cl/ (accessed on 21 June 2018). (In Spanish)

47. National Institute Statistics. Statistics, Databases; Instituto Nacional de Estadísticas: Santiago, Chile, 2021; Available online: https:/ / www.ine.cl/estadisticas (accessed on 21 August 2018). (In Spanish)

48. Undersecretary of Regional and Administrative Development. National Municipal Information System; Subsecretaría de Desarrollo Regional Administrativo: Santiago, Chile, 2021; Available online: http:/ / www.sinim.cl/ (accessed on 21 July 2018). (In Spanish)

49. Library of Congress of Chile. Chilean Constitution; Chilean Congress; Valparaíso, Chile. 2021. Available online: https: //www.bcn.cl/ (accessed on 21 April 2018). (In Spanish).

50. Library of Congress. Constitutional Law No. 18.695 of Municipalities; Library of Congress: Valparaíso, Chile, 2021; Available online: https: / / www.bcn.cl/leychile/navegar?idNorma=251693 (accessed on 27 December 2020). (In Spanish)

51. Organisation for Economic Co-Operation and Development. Making Decentralisation Work in Chile; OECD: Paris, France, 2017.

52. Ministry of Housing and Urban Development. Quality of Life Surveys; Databases (2007, 2010, 2012, 2015); Ministry of Housing and Urban Development: Santiago, Chile, 2021. Available online: https://calidaddevida.minvu.gob.cl/documentos--encuesta--de-percepcion--de--calidad--de--vida--urbana (accessed on 28 June 2020). (In Spanish)

53. Ministry of Social Development. Socioeconomic Characterization Surveys; Databases (2009, 2011, 2013, 2015); Ministry of Social Development: Santiago, Chile, 2021; Available online: http://observatorio.ministeriodesarrollosocial.gob.cl/ (accessed on 28 September 2020). (In Spanish)

54. Valdivieso, P.; Andersson, K.P. Local politics of environmental disaster risk management: Institutional analysis and lessons from Chile. J. Environ. Dev. 2017, 26, 51-81. [CrossRef]

55. Valdivieso, P. Municipal governance, environmental management and disaster risk reduction in Chile. Bull. Lat. Am. Res. 2017, 36, 440-458. [CrossRef]

56. National Fund for Scientific and Technological Research. Institutional Drivers of Local Environmental Management in Chile; FONDECYT Grant 1181282; Universidad Austral: Valdivia, Chile, 2021; Available online: https://sites.google.com/view/ localenvironmentalgovernance/home) (accessed on 22 November 2020). (In Spanish)

57. Ministry of Public Works. Road Network and Distances; Ministerio de Obras Públicas, Dirección de Vialidad: Santiago, Chile, 2021; Available online: http:/ / www.vialidad.cl/productosyservicios/Paginas/Distancias.aspx (accessed on 22 May 2018). (In Spanish)

58. Balbontín, R.; Escobar, L.; Seemann, A. Financing of Regional Governments in Chile; Dirección de Presupuesto: Santiago, Chile, 2017; Available online: https:/ /www.dipres.gob.cl/598/articles-160346_doc_pdf.pdf (accessed on 29 July 2018). (In Spanish)

59. Ministry of Environment. Chile's Second Biennial Update Report to the United Framework Convention on Climate Change; Ministry of Environment: Santiago, Chile, 2016; Available online: https://unfccc.int/resource/docs/natc/chinc2e.pdf (accessed on 4 April 2018). (In Spanish)

60. Organisation for Economic Co-Operation and Development. Gaps and Governance Standards of Public Infrastructure in Chile: Infrastructure Governance Review; OECD: Paris, France, 2017.

61. Valdivieso, P. Institutional and social enablers for governance of environmental risks at the local scale. Analysis with Chilean municipalities. Opinião Pública 2017, 23, 538-573. [CrossRef] 
62. Organisation for Economic Co-Operation and Development/Economic Commission for Latin America and the Caribbean. OECD Environmental Performance Reviews: Chile 2016; OECD: Paris, France, 2016.

63. Meteored. Climate Information; Meteored: Santiago, Chile, 2018; Available online: https://www.meteored.cl/ (accessed on 29 April 2018). (In Spanish)

64. Educar Chile. Climate Map of Chile; Ministerio de Educación, Fundación Chile: Santiago, Chile, 2018; Available online: http: / / www.educarchile.cl/ech/pro/app/detalle?id=130965 (accessed on 2 May 2018). (In Spanish)

65. Organisation for Economic Co-Operation and Development/Economic Commission for Latin America and the Caribbean. OECD Environmental Performance Reviews: Chile 2005; OECD: Paris, France, 2005.

66. Ministry Environment. National Surveys on Environment (2014, 2015, 2016); Ministry Environment: Santiago, Chile, 2021; Available online: https: / / mma.gob.cl/encuestas-nacionales-del-medio-ambiente (accessed on 29 September 2020). (In Spanish)

67. Economic Commission for Latin America and the Caribbean. The Economy of climate change in Latin America; Economic Commission for Latin America and the Caribbean: Santiago, Chile, 2015. (In Spanish)

68. United States Geological Survey (USGS) Earthquake Hazards Program; Department of the Interior: Washington, DC, USA. 2018. Available online: http: / / earthquake.usgs.gov / (accessed on 22 July 2018). (In Spanish)

69. National Forest Corporation. Forest Fires; Corporación Forestal Nacional, Ministry of Agriculture: Santiago, Chile, 2021; Available online: https: / / www.conaf.cl/incendios--forestales / (accessed on 20 July 2020). (In Spanish)

70. National Aeronautics and Space Administration (NASA). Earth Observatory; National Aeronautics and Space Administration: Washington, DC, USA, 2018. Available online: https:/ / earthobservatory.nasa.gov / about (accessed on 17 July 2020). (In Spanish)

71. Centre for Research on the Epidemiology of Disasters (CRED) Annual Disaster STATISTICAL Review; Centre for Research on the Epidemiology of Disasters: Louvain-la-Neuve, Belgium, 2011.

72. Alliance Development Works. World Risk Report 2015; United Nations University, Institute for Environment and Human Security: Bonn, Germany; Available online: http:/ / collections.unu.edu/collection/UNU:1901 (accessed on 15 July 2018). (In Spanish)

73. National Seismological Center. Latest Earthquake; Universidad de Chile: Santiago, Chile, 2015; Available online: http://www. sismologia.cl/ (accessed on 10 July 2018). (In Spanish)

74. National Oceanic and Atmospheric Administration (NOAA). National Environmental Satellite Data and Information Service; National Oceanic and Atmospheric Administration: Washington, DC, USA, 2018. Available online: https://www.ospo.noaa.gov/ Organization/About/contact.html (accessed on 9 July 2018). (In Spanish)

75. National Geology and Mining Service. Volcanic Hazards; Servicio Nacional de Geología y Minería, Santiago, Chile. 2018. Available online: http:/ / www.sernageomin.cl/archivos/PeligrosVolcanicosdeChile.pdf (accessed on 2 July 2018). (In Spanish).

76. United Nations International Strategy for Disaster Reduction. DesInventar; United Nations International Strategy for Disaster Reduction: Geneva, Switzerland, 2018; Available online: https: / / www.desinventar.net/ (accessed on 27 July 2018). (In Spanish)

77. World Bank. Country Note on Climate Change Aspects in Agriculture; World Bank: New York, NY, USA, 2009.

78. National Emergency Office. National Policy for Disaster Risk Reduction; Oficina Nacional de Emergencia (ONEMI): Santiago, Chile, 2014. Available online: https://www.onemi.gov.cl/planes-nacionales / (accessed on 22 April 2018). (In Spanish)

79. Nahuelpan, E.; Varas, J. The Earthquake in Chile: Medico-Legal Statistics; Instituto Médico Legal: Santiago, Chile, 2013; Available online: http:/ /icy.sml.gob.cl/wp-content/uploads/2020/01/Revista-Investigacion-Forense-Numero-2.pdf (accessed on 22 November 2018). (In Spanish)

80. Ministry of Interior. Earthquake and Tsunami Reconstruction Plan; Ministerio del Interior: Santiago, Chile, 2010; Available online: https:/ / www.preventionweb.net/files/28726_plandereconstruccinagosto2010.pdf (accessed on 22 November 2018). (In Spanish)

81. Astroza, M.; Ruiz, S.; Astroza, R.; Molina, J. Seismic Intensities 2010; Universidad de Chile: Santiago, Chile, 2014; Available online: http:/ /dgf.uchile.cl/ \{\}sruiz/Papers/books/107-126.pdf (accessed on 25 May 2020). (In Spanish)

82. Ministry of Social Development. Integrated Projects Bank; Ministerio de Desarrollo Social: Santiago, Chile, 2021; Available online: https:/ / bip.ministeriodesarrollosocial.gob.cl/bip2-trabajo/app/login (accessed on 25 September 2020). (In Spanish)

83. National Emergency Office. Underlying Risk Factors; Oficina Nacional de Emergencia: Santiago, Chile, 2014; Available online: https:/ /geoportalonemi.maps.arcgis.com/apps/MapSeries/index.html?appid=a6775bda6d054305a2482efc999d9890 (accessed on 22 April 2018). (In Spanish)

84. Satterthwaite, D.; Huq, S.; Pelling, M.; Reid, H.; Romero Lankao, P. Adapting to Climate Change in Urban Areas; International Institute for Environment and Development (IIED): London, UK, 2007.

85. Organisation for Economic Co-Operation and Development. Investing in Climate, Investing in Growth; OECD: Paris, France, 2017.

86. Ostrom, E.; Schroeder, L.; Wynne, S. Institutional Incentives and Sustainable Development: Infrastructure Policies in Perspective; Westview Press: Boulder, CO, USA, 1993.

87. Ostrom, V.; Ostrom, E. Public Choice: A Different Approach to the Study of Public Administration. Public Adm. Rev. 1971, 31, 203-216. [CrossRef]

88. LSE Cities, UN-Habitat. How Cities are Governed: Building a Global Database for Current Models of Urban Governance; London School of Economics and Political Science: London, UK, 2016; Available online: https://urbangovernance.net/en/ (accessed on 22 January 2020). (In Spanish)

89. Roberts, D. Prioritizing climate change adaptation and local level resilience in Durban, South Africa. Environ. Urban. 2010, 22, 397-413. [CrossRef] 
90. Aylett, A. The Socio-institutional Dynamics of Urban Climate Governance: A Comparative Analysis of Innovation and Change in Durban (KZN, South Africa) and Portland (OR, USA). Urban Stud. 2013, 50, 1386-1402. [CrossRef]

91. Sánchez-Rodríguez, R. Learning to adapt to climate change in urban areas. A review of recent contributions. Curr. Opin. Environ. Sustain. 2009, 1, 201-206. [CrossRef]

92. Nuno, F.; Rode, P.; McQuarrie, M. New urban governance: A review of current themes and future priorities. J. Urban Aff. 2018, 41,1-19.

93. Bakera, I.; Peterson, A.; Brown, G.; McAlpinea, C. Local government response to the impacts of climate change: An evaluation of local climate adaptation plans. Urban Plan. 2012, 107, 127-136. [CrossRef]

94. Kiunsi, R. The constraints on climate change adaptation in a city with a large development deficit: The case of Dar es Salaam Environ. Urban. 2013, 25, 321-337. [CrossRef]

95. Quiroz, D. Las ciudades y el cambio climático: El caso de la política climática de la Ciudad de México. Estud. Demográficos Urbanos. 2013, 28, 343-382. [CrossRef]

96. Groven, K.; Aall, C.; van den Berg, M.; Carlsson-Kanyama, A.; Coenen, F. Integrating climate change adaptation into civil protection: Comparative lessons from Norway, Sweden and the Netherlands. Local Envron. Int. J. Justice Sustain. 2012, 17, 679-694. [CrossRef]

97. Burby, R.; Deyle, R.; Godschalk, D.; Olshansky, R. Creating hazard resilient communities through land-use planning. Nat. Hazards Rev. 2000, 1, 99-106. [CrossRef]

98. Jensen, A.; Nielsen, H.; Nielsen, M. Climate Adaptation in Local Governance: Institutional Barriers in Danish Municipalities; Arhus University, DCE—Danish Centre for Environment and Energy: Aarhus, Denmark, 2016; Available online: http://dce2.au.dk/ pub/SR104.pdf (accessed on 20 February 2020). (In Spanish)

99. Tullock, G. The Politics of Bureaucracy; Public Affairs Press: Washington, DC, USA, 1965; p. 69.

100. Wheeler, S.M. State and municipal climate change plans: The first generation. J. Am. Plan Assoc. 2008, 74, 481-496. [CrossRef]

101. Bridget, K. Local Bureaucrats and Climate Change Adaptation; Siracuse University, New York, NY, USA. 2018. Available online: https:/ / surface.syr.edu/etd/895 (accessed on 23 June 2021). (In Spanish).

102. Lavee, E.; Cohen, N. How street-level bureaucrats become policy entrepreneurs: The case of urban renewal. Governance 2019, 32, 475-492. [CrossRef]

103. Dahl, R. Who Governs? Democracy and Power in an American City; Yale University Press: New Haven, CT, USA, 1961.

104. Liefferink, D.; Wurzel, R.K.W. Environmental leaders and pioneers: Agents of change? J. Eur. Public Policy 2017, 24, 951-968. [CrossRef]

105. De la Porte, C.; Natali, D. Agents of institutional change in EU policy: The social investment moment. J. Eur. Public Policy 2018, 25, 828-843. [CrossRef]

106. Graen, G.B. Overview of future research directions for team leadership. In The Oxford Handbook of Leadership; Rumsey, M., Ed.; Oxford University Press: New York, NY, USA, 2013; pp. 167-183.

107. Blau, J.R.; Alba, R.D. Empowering nets of participation. Adm. Sci. Q. 1982, 27, 363-379. [CrossRef]

108. Balkundi, P.; Kilduff, M. The ties that lead: A social network approach to leadership. Leadersh. Q. 2005, 16, 419-439. [CrossRef]

109. Bell, S. Do we really need a new "constructivist institutionalism" to explain institutional change? Br. J. Polit. Sci. 2011, 41, 883-906. [CrossRef]

110. Bhavnani, R.; Lee, A. Local Embeddedness and Bureaucratic Performance: Evidence from India. J. Politics 2018, 80, 71-87. [CrossRef]

111. Taylor, A.; Cocklin, C.; Brown, R.; Wilson-Evered, E. An investigation of champion-driven leadership processes. Lead. Q. 2011, 22, 412-433. [CrossRef]

112. Li, X.; Han, M.; Cohen, G.L.; Markus, H.R. Passion matters but not equally everywhere: Predicting achievement from interest, enjoyment, and efficacy in 59 societies. PNAS 2021, 118, e2016964118. [CrossRef] [PubMed]

113. Szreter, S.; Woolcock, M. Health by association? Social capital, social theory, and the political economy of public health. Int. J. Epidemiol. 2004, 33, 650-667. [CrossRef]

114. Palermo, V.; Bertoldi, P.; Apostolou, M.; Kona, A.; Rivas, S. Assessment of climate change mitigation policies in 315 cities in the Covenant of Mayors initiative. Sustain. Cities Soc. 2020, 60, 102258. [CrossRef]

115. Bentzen, T.; Lo, C.; Winsvold, M. Strengthening local political leadership through institutional design: How and why. Local Gov. Stud. 2020, 46, 483-504. [CrossRef]

116. Walkowiak, K.; Bernaciak, A. Leadership Styles of Rural Leaders in the Context of Sustainable Development Requirements: A Case Study of Commune Mayors in the Greater Poland Province, Poland. Sustainability 2020, 12, 2676. [CrossRef]

117. Granberg, M.; Bosomworth, K.; Moloney, S.; Kristianssen, A.-C.; Fünfgeld, H. Can Regional-Scale Governance and Planning Support Transformative Adaptation? A Study of Two Places. Sustainability 2019, 11, 6978. [CrossRef]

118. Heinelt, H. The Changing Context of Local Democracy. In Role Perception and Behaviour of Municipal Councillors; Routledge: Oxfordshire, UK, 2020.

119. Greenwood, R.; Suddaby, R. Institutional entrepreneurship in mature fields: The big five accounting firms. Acad. Manag. J. 2006, 49, 27-48. [CrossRef]

120. Schotter, A.P.J.; Meyer, K.; Wood, G. Organizational and comparative institutionalism in international HRM: Toward an integrative research agenda. Hum. Resour. Manage. 2021, 60, 205-227. [CrossRef] 
121. March, J.G.; Olsen, J.P. Ambiguity and Choice in Organizations. Am. Political Sci. Rev. 1976, 78, 734-749.

122. Meyer, J.W.; Rowan, B. Institutionalized Organizations: Formal Structure as Myth and Ceremony. Am. J. Sociol. 1977, 83, 440-463. [CrossRef]

123. Ruef, M.; Richard, S.A. Multidimensional Model of Organizational Legitimacy: Hospital Survival in Changing Institutional Environments. Adm. Sci. Q. 1998, 43, 877-904. [CrossRef]

124. Dacin, T.; Goldstein, J.; Scott, W.R. Institutional theory and institutional change: Introduction to the special research forum. Acad. Manag. J. 2002, 45, 45-56. [CrossRef]

125. Foster, J.; Jones, J. Rule Orientation and Bureaucratic Reform. Am. J. Political Sci. 1978, 22, 348-363. [CrossRef]

126. Wilson, J.Q. Bureaucracy: What Government Agencies Do and Why They Do It; Basic Books: New York, NY, USA, 1989.

127. Kruis, J.; Maris, G.; Marsman, M.; Bolsinova, M.; Van der Maas, H. Deviations of rational choice: An integrative explanation of the endowment and several context effects. Sci. Rep. 2020, 10, 16226. [CrossRef] [PubMed]

128. Lapuente, V.; Suzuki, K. Politicization. Bureaucratic Legalism, and Innovative Attitudes in the Public Sector. Public Admin. Rev. 2020, 80, 454-467. [CrossRef]

129. Scott, I.; Gong, T. Coordinating government silos: Challenges and opportunities. GPPG 2021, 1, 20-38. [CrossRef]

130. Agrawal, A.; Ribot, J. Accountability in decentralization. J. Dev. Areas 1999, 33, 473-502.

131. Heimstädt, M.; Dobusch, L. Transparency and Accountability: Causal, Critical and Constructive Perspectives. Organ. Theory 2020. [CrossRef]

132. Birkmann, J.; Garschagen, M.; Kraas, F.; Quang, N. Adaptive urban governance: New challenges for the second generation of urban adaptation strategies to climate change. Sustain. Sci. 2010, 5, 185-206. [CrossRef]

133. Bae, J.; Feiock, R. Forms of Government and Climate Change Policies in US Cities. Urban Stud. 2013, 50, 776-788. [CrossRef]

134. Solecki, W.; Rosenzweig, C. Indicators and monitoring systems for urban climate resiliency. Clim. Chang. 2020, 163, 1815-1837. [CrossRef]

135. Weber, M. Economy and Society; Bedminster Press: New York, NY, USA, 1968.

136. Sorensen, A. Public Norms and Aspirations: The Turn to Institutions in Action. Plan. Theory Pract. 2020, 21, 808-811. [CrossRef]

137. DiMaggio, P.J.; Powell, W.W. The New Institutionalism in Organizational Analysis; University of Chicago Press: Chicago, IL, USA, 1991.

138. Hallett, T.; Hawbaker, A. The case for an inhabited institutionalism in organizational research: Interaction, coupling, and change reconsidered. Theor. Soc. 2021, 50,1-32. [CrossRef]

139. Seo, M.G.; Creed, W.E.D. Institutional contradictions, praxis and institutional change: A dialectical perspective. Acad. Manag. Rev. 2002, 27, 222-247. [CrossRef]

140. West, W. Structuring Administrative Discretion: The Pursuit of Rationality and Responsiveness. Am. J. Political Sci. 1984, 28, 340-360. [CrossRef]

141. Stein, R. Municipal Public Employment: An Examination of Intergovernmental Influences. Am. J. Political Sci. 1984, 28, 636-653. [CrossRef]

142. March, C. Exploration and Exploitation in Organizational Learning. Organ. Sci. 1991, 2, 71-87. [CrossRef]

143. Tilman, A.R.; Plotkin, J.B.; Akçay, E. Evolutionary games with environmental feedbacks. Nat. Commun. 2020, 11, 915. [CrossRef]

144. Sommerer, T.; Tallberg, J. Diffusion Across International Organizations: Connectivity and Convergence. Int. Organ. 2019, 73, 399-433. [CrossRef]

145. Ostrom, V.; Tiebout, C.; Warren, R. The Organization of Government in Metropolitan Areas: A Theoretical Inquiry. Am. Political Sci. Rev. 1961, 55, 831-842. [CrossRef]

146. Hooghe, L.; Marks, G.A. A postfunctionalist theory of multilevel governance. Br. J. Politics Int. Relat. 2020, 22, 820-826. [CrossRef]

147. Gupta, J.; Lasage, R.; Stam, T. National efforts to enhance local climate policy in the Netherlands. Environ. Sci. 2007, 4, 171-182. [CrossRef]

148. Urwin, K.; Jordan, A. Does public policy support or undermine climate change adaptation? Exploring policy interplay across different scales of governance. Glob. Environ. Chang. 2008, 18, 180-191. [CrossRef]

149. Di Gregorio, M.; Fatorelli, L.; Paavola, J.; Locatelli, B.; Pramova, E.; Nurrochmat, D.R.; May, P.H.; Brockhaus, M.; Maya, I.; Dyah, S. Multi-level governance and power in climate change policy networks. Glob. Environ. Chang. 2019, 54, 64-77. [CrossRef]

150. Næss, L.O.; Bang, G.; Eriksen, S.; Vevatne, J. Institutional adaptation to climate change: Flood responses at the municipal level in Norway. Glob. Environ. Chang. 2005, 15, 125-138. [CrossRef]

151. Gillard, R.; Gouldson, A.; Paavola, J.; Van Alstine, J. Can national policy blockages accelerate the development of polycentric governance? Evidence from climate change policy in the United Kingdom. Glob. Environ. Chang. 2017, 45, 174-182. [CrossRef]

152. Azhoni, A.; Holman, I.; Jude, S. Adapting water management to climate change: Institutional involvement, inter-institutional networks and barriers in India. Glob. Environ. Chang. 2017, 44, 144-157. [CrossRef]

153. Wooldridge, J.M. Econometric Analysis of Cross Section and Panel Data; Massachusetts Institute of Technology (MIT): Cambridge, MA, USA, 2010.

154. Dawson, J.F. Moderation in Management Research: What, Why, When, and How. J. Bus Psychol. 2013, 29, 1-19. [CrossRef]

155. Garreaud, R.; Alvarez-Garreton, C.; Barichivich, J.; Boisier, J.P.; Christie, D.; Galleguillos, M.; LeQuesne, C.; McPhee, J.; ZambranoBigiarini, M. The 2010-2015 megadrought in central Chile: Impacts on regional hydroclimate and vegetation. Hydrol. Earth Syst. Sci. 2017, 21, 6307-6327. [CrossRef] 
156. Carrasco, C.; Rosner, R. The Chilean electricity sector confronts climate change. Bull. At. Sci. 2017, 73, 395-403. [CrossRef]

157. Baselli, G.; Contreras, F.; Lillo, M.; Marín, M.; Carrasco, R. Optimal decisions for salvage logging after wildfires. Omega 2020, 96, 1-9. [CrossRef]

158. Mazzorana, B.; Picco, L.; Rainato, R.; Iroumé, A.; Ruiz-Villanueva, V.; Rojas, C.; Valdebenito, G.; Iribarren-Anacona, B.; Melnick, D. Cascading processes in a changing environment: Disturbances on fluvial ecosystems in Chile and implications for hazard and risk management. Sci. Total Environ. 2019, 655, 1089-1103. [CrossRef]

159. Barcaza, G.; Nussbaumer, S.; Tapia, G.; Valdés, J.; García, J.; Videla, Y.; Arias, V. Glacier inventory and recent glacier variations in the Andes of Chile, South America. Ann. Glaciol. 2017, 58, 166-180. [CrossRef]

160. Bronfman, N.C.; Cisternas, P.C.; López-Vázquez, E.; Cifuentes, L.A. Trust and risk perception of natural hazards: Implications for risk preparedness in Chile. Nat. Hazards 2016, 81, 307-327. [CrossRef]

161. Ruiz, S.; Madariaga, R. Historical and recent large megathrust earthquakes in Chile. Tectonophysics 2018, 733, 37-56. [CrossRef]

162. Iribarren, P.; Mackintosh, A.; Norton, K.P. Hazardous processes and events from glacier and permafrost areas: Lessons from the Chilean and Argentinean Andes. Earth Surf. Process. Landforms. 2014, 40, 2-21. [CrossRef]

163. Moernaut, J.; Van Daele, M.; Fontijn, K.; Heirman, K.; Kempf, P.; Pino, M.; Valdebenito, G.; Urrutia, R.; Strasser, M.; De Batist, M. Larger earthquakes recur more periodically. New insights in the megathrust earthquake cycle from lacustrine Turbidite Records in South Central Chile. Earth Planet. Sci. Lett. 2018, 481, 9-19. [CrossRef]

164. Úbeda, Z.; Sarricolea, P. Wildfires in Chile: A review. Glob. Planet. Chang. 2016, 146, 152-161. [CrossRef]

165. Rojas, O.; Mardones, M.; Rojas, C.; Martínez, C.; Flores, L. Urban Growth and Flood Disasters in the Coastal River Basin of South-Central Chile (1943-2011). Sustainability 2017, 9, 195. [CrossRef]

166. Wilson, R.; Glasser, N.; Reynolds, J.; Harrison, S.; Iribarren, P.; Schaefer, M.; Shannon, S. Glacial lakes of the central and Patagonian Andes. Glob. Planet. Chang. 2018, 162, 275-291. [CrossRef]

167. Google. Satelital Map. 2021. Available online: https:// satellite--map.gosur.com/es/ (accessed on 22 September 2020).

168. National Agroclimatic Network. Agromet. 2021; Ministerio de Agricultura: Santiago, Chile, 2021. Available online: https: / / www.agromet.cl/ (accessed on 22 August 2020). (In Spanish)

169. National Office of Emergencies. Digital Repository; Oficina Nacional de Emergencia: Santiago, Chile, 2021. Available online: https:/ / repositoriodigital.onemi.gov.cl/ (accessed on 12 August 2018). (In Spanish)

170. Gooogle Earth. Lawrence, Kansas, USA. 2021. Available online: https:/ / earth.google.com/web/ (accessed on 20 August 2018).

171. General Water Office. Decrees; Ministry of Public Works: Santiago, Chile, 2021; Available online: https://dga.mop.gob.cl/ administracionrecursoshidricos/decretosZonasEscasez/Paginas/default.aspx (accessed on 25 July 2018). (In Spanish)

172. Library of the Congress. Decrees Library of the Congress: Valparapíso, Chile. 2021. Available online: https://www.bcn.cl/ (accessed on 22 July 2020). (In Spanish).

173. National Geology and Mining Service. Main Disasters that Have Occurred Since 1980 in Chile; Servicio Nacional de Geología y Minería, Santiago, Chile. 2006. Available online: http://sitiohistorico.sernageomin.cl/pdf/presentaciones-geo/Primer-CatastroNacional-Desastres-Naturales.pdf (accessed on 7 June 2018). (In Spanish).

174. Ministry of Environment. Digital Base of Clima; Ministerio del Medioambiente: Santiago, Chile, 2021; Available online: http: / / basedigitaldelclima.mma.gob.cl/study/one (accessed on 10 June 2019). (In Spanish)

175. Meteorological Directorate. Climate Services; General Directorate of Civil Aviation: Santiago, Chile, 2021. Available online: http: / / www.meteochile.cl/PortalDMC--web/index.xhtml (accessed on 22 July 2019). (In Spanish)

176. United Nations Development Programme. The Trajectories of Human Development in the Chilean Communities (1994-2003); United Nations Development Chile: Santiago, Chile, 2006. (In Spanish)

177. Electoral Service. Statistics; Servicio Electoral: Santiago, Chile, 2021. Available online: www.servel.cl (accessed on 22 December 2020). (In Spanish)

178. National Council for Transparency. Open Data; Consejo para la Transparencia: Santiago, Chile, 2018. Available online: https: / / www.consejotransparencia.cl/datos--abiertos/ (accessed on 15 July 2018). (In Spanish)

179. Ministry of Finances. Register of Collaborators; Ministerio de Hacienda: Santiago, Chile, 2021. Available online: https: / www. registros19862.cl/reportes/transferencias/reporte/ingresadas (accessed on 15 November 2018). (In Spanish)

180. Directorate of Budgets, Ministry of Finances. Instructions for Execution of the Budget Law in Public Sector; Dirección de Presupuesto (DIPRES): Santiago, Chile, 2021. Available online: http:/ / www.dipres.gob.cl/598/w3-propertyvalue-15954.html (accessed on 28 July 2018). (In Spanish)

181. Techo. National Land Registry of Camps 2005, 2007, 2013, 2014, 2015, 2016. Available online: http://datos.techo.org/tr/dataset/ catastro-campamentos-2016 (accessed on 23 January 2021). (In Spanish).

182. World Bank. Chile, Data; World Bank: New York, NY, USA, 2021. Available online: https://data.worldbank.org/country/chile (accessed on 23 January 2021). (In Spanish)

183. Andersson, K.; Gordillo, G.; van Laerhoven, F. Local Governments and Rural Development: Comparing Lessons from Brazil, Chile, Mexico, and Peru; University of Arizona Press: Tucson, AZ, USA, 2009.

184. Valdivieso, P.; Bernas, J. Difficulties of the approximation of transparency as a command and control policy: Chilean experience with municipalities. Rev. CLAD Reforma Democr. 2014, 58, 201-234.

185. Comptroller General of the Republic. Audit Reports; Contraloría General de la República, Santiago, Chile, 2021. Available online: https:/ / www.contraloria.cl/web/cgr/\# (accessed on 22 July 2019). (In Spanish). 
186. Directorate of Budgets, Ministry of Finances. Final Report Neighborhood Improvement Program; Ministry of Finance: Santiago, Chile, 2012. Available online: https://www.dipres.gob.cl/597/articles-163123_informe_final.pdf (accessed on 2 October 2019). (In Spanish)

187. Directorate of Budgets, Ministry of Finances. Management Strengthening Program; Ministry of Finance: Santiago, Chile, 2010. Available online: https://www.dipres.gob.cl/597/articles-141149_r_ejecutivo_institucional.pdf (accessed on 2 October 2019). (In Spanish)

188. Dilling, L.; Pizzi, E.; Berggren, J.; Ravikumar, A.; Andersson, K. Drivers of adaptation: Responses to weather- and climate-related hazards in 60 local governments in the Intermountain Western. U.S. Environ. Plan. A 2017, 49, 2628-2648. [CrossRef]

189. Cameron, A.C.; Trivedi, P.K. Microeconometrics Using Stata; Stata Press: College Station, TX, USA, 2010.

190. Wolter, K.M. Taylor Series Methods. Introduction to Variance Estimation; Springer: New York, NY, USA, 1985.

191. Agresti, A. Categorical Data Analysis; John Wiley and Sons: New York, NY, USA, 1990.

192. Lindstrom, D. Schaum's Easy Outline of Statistics. McGraw-Hill Education: New York, NY, USA, 2010.

193. Superintendency of Pensions. Data on Pensions; Superintendencia de Pensiones: Santiago, Chile, 2021. Available online: https:/ / www.spensiones.cl (accessed on 25 December 2020). (In Spanish)

194. Municipality of Cauquenes. Annual Public Accounts, Community Development Plans, Meeting Minutes of Municipal Councils, Municipal Budgets, Staff, Regulatory Framework, Resolutions with Effects on Third Parties: 2009-2016; Municipality of Cauquenes: Cauquenes, Chile, 2021. Available online: https:/ / www.cauquenes.cl/ (accessed on 13 June 2018). (In Spanish)

195. Municipality of Concepción. Annual Public Accounts, Community Development Plans, Meeting Minutes of Municipal Councils, Municipal Budgets, Staff, Regulatory Framework, Resolutions with Effects on Third Parties. 2009-2016; Municipality of Concepción: Concepción, Chile, 2021. Available online: https: / / concepcion.cl/ (accessed on 15 June 2018). (In Spanish)

196. Municipality of La Florida. Annual Public Accounts, Community Development Plans, Meeting Minutes of Municipal Councils, Municipal Budgets, Staff, Regulatory Framework, Resolutions with Effects on Third Parties. 2009-2016; Municipality of La Florida: La Florida, Chile, 2021. Available online: https:/ / www.laflorida.cl/sitio/ (accessed on 17 June 2018). (In Spanish)

197. Municipality of Lebu. Annual Public Accounts, Community Development Plans, Meeting Minutes of Municipal Councils, Municipal Budgets, Staff, Regulatory Framework, Resolutions with Effects on Third Parties. 2009-2016; Municipality of Lebu: Lebu, Chile, 2021. Available online: https: / / www.lebu.cl/ (accessed on 19 June 2018). (In Spanish)

198. Municipality of Osorno Annual Public Accounts. Community Development Plans, Meeting Minutes of Municipal Councils, Municipal Budgets, Staff, Regulatory Framework, Resolutions with Effects on Third Parties 2009-2016; Municipality of Osorno: Osorno, Chile, 2021; Available online: https:/ / www.municipalidadosorno.cl/ (accessed on 21 June 2018). (In Spanish)

199. Municipality of Panguipulli. Annual Public Accounts, Community Development Plans, Meeting Minutes of Municipal Councils, Municipal Budgets, Staff, Regulatory Framework, Resolutions with Effects on Third Parties. 2009-2016; Municipality of Panguipulli: Panguipulli, Chile, 2021; Available online: panguipulli.cl (accessed on 22 June 2018). (In Spanish)

200. Municipality of Puerto Montt. Annual Public Accounts, Community Development Plans, Meeting Minutes of Municipal Councils, Municipal Budgets, Staff, Regulatory Framework, Resolutions with Effects on Third Parties. 2009-2016; Municipality of Puerto Montt: Puerto Montt, Chile, 2021. Available online: https:/ /www.puertomontt.cl/servicios/municipio--en--linea/ (accessed on 24 June 2018). (In Spanish)

201. Municipality of Renca. Annual Public Accounts, Community Development Plans, Meeting Minutes of Municipal Councils, Municipal Budgets, Staff, Regulatory Framework, Resolutions with Effects on Third Parties. 2009-2016; Municipality of Renca: Renca, Chile, 2021. Available online: https:/ / www.renca.cl/permisos--de--circulacion/ (accessed on 26 June 2018). (In Spanish)

202. Municipality of Valparaíso. Annual Public Accounts, Community Development Plans, Meeting Minutes of Municipal Councils, Municipal Budgets, Staff, Regulatory Framework, Resolutions with Effects on Third Parties. 2009-2016; Municipality of Valparaíso: Valparaíso, Chile, 2021; Available online: https: / / www.municipalidaddevalparaiso.cl/ (accessed on 28 June 2018). (In Spanish)

203. ProCalidad. Índice Nacional de Satisfacción de Clientes. Procalidad: Santiago, Chile. Available online: http:/ /www.procalidad. $\mathrm{cl} /$ indice-nacional-de-satisfaccion-de-clientes / (accessed on 3 September 2020). (In Spanish).

204. Library of Congress. Law No 18834 Administrative Statute; Library of Congress: Valparaíso, Chile, 2021. Available online: https:/ / www.bcn.cl/leychile/navegar?idNorma=30256 (accessed on 27 December 2020). (In Spanish)

205. Vallejos, A.; Valdivieso, P. Towards second-order public policies in Latin America. Andamios 2014, 11, $323-352$.

206. Fábrega, J.; González, J.; Lindh, J. Polarization and Electoral Incentives: The End of the Chilean Consensus Democracy, $1990-2014$. Lat. Am. Politics Soc. 2018, 60, 49-68. [CrossRef]

207. Pérez, A.; Luján, D. Cercanía, favor, lealtad. Clientelismo en dos municipalidades chilenas. Sociológica 2018, 33, 235-268. 